\title{
Deformation of intrasalt competent layers in different modes of salt tectonics
}

\author{
Mark G. Rowan ${ }^{1}$, Janos L. Urai ${ }^{2}$, J. Carl Fiduk ${ }^{3}$, and Peter A. Kukla ${ }^{4}$ \\ ${ }^{1}$ Rowan Consulting, Inc., Boulder, CO 80302, USA \\ ${ }^{2}$ Institute for Structural Geology, Tectonics and Geomechanics, RWTH Aachen University, 52056 Aachen, Germany \\ ${ }^{3}$ Fiduk Consulting LLC, Houston, TX 77063, USA \\ ${ }^{4}$ Geological Institute, Energy and Mineral Resources, RWTH Aachen University, 52056 Aachen, Germany
}

Correspondence: Mark G. Rowan (mgrowan@frii.com)

Received: 7 March 2019 - Discussion started: 25 March 2019

Revised: 2 June 2019 - Accepted: 5 June 2019 - Published: 28 June 2019

\begin{abstract}
Layered evaporite sequences (LESs) comprise interbedded weak layers (halite and, commonly, bittern salts) and strong layers (anhydrite and usually non-evaporite rocks such as carbonates and siliciclastics). This results in a strong rheological stratification, with a range of effective viscosity up to a factor of $10^{5}$. We focus here on the deformation of competent intrasalt beds in different endmember modes of salt tectonics, even though combinations are common in nature, using a combination of conceptual, numerical, and analog models, and seismic data. In bedding-parallel extension, boudinage of the strong layers forms ruptured stringers, within a halite matrix, that become more isolated with increasing strain. In bedding-parallel shortening, competent layers tend to maintain coherency while forming harmonic, disharmonic, and polyharmonic folds, with the rheological stratification leading to buckling and fold growth by beddingparallel shear. In differential loading, extension and the resultant stringers dominate beneath suprasalt depocenters, while folded competent beds characterize salt pillows. Finally, in passive diapirs, stringers generated by intrasalt extension are rotated to near vertical and encased in complex folds during upward flow of salt. In all cases, strong layers are progressively removed from areas of salt thinning and increasingly disrupted and folded in areas of salt growth as deformation intensifies. The varying styles of intrasalt deformation impact seismic imaging of LES and associated interpretations. Ruptured stringers are often visible where they have low dips, as in slightly extended salt layers or beneath depocenters, but are poorly imaged in passive diapirs due to steep dips. In contrast, areas of slightly to moderately shortened salt typically
\end{abstract}

have well-imaged, mostly continuous intrasalt reflectors, although seismic coherency decreases as deformation intensifies. Similarly, wells are most likely to penetrate strong layers in contractional structures and salt pillows, less likely in extended salt because they might drill between stringers, and unlikely in tall passive diapirs because the stringers are near vertical. Thus, both seismic and well data may be interpreted to suggest that diapirs and other areas of more intense intrasalt deformation are more halite rich than is actually the case.

\section{Introduction}

The "salt" of ancient global salt basins never comprises solely halite (or rocksalt). Instead, the stratigraphic unit that forms salt diapirs or serves as a salt detachment is better termed a layered evaporite sequence (LES) consisting of interbedded halite, other evaporites, and usually non-evaporite rocks. These sequences were deposited in isolated basins in arid climates, with the surface of the evaporitic brine ranging from very shallow to $1.5 \mathrm{~km}$ or more beneath global sea level (see Warren, 2016).

The most common non-halite evaporite mineral is gypsum/anhydrite (used interchangeably here) because, ignoring minor carbonate evaporites, it precipitates prior to halite as a body of water is evaporated (e.g., Warren, 2016). Anhydrite may occur in layers distributed throughout the LES but is often concentrated near the base and sometimes near the top due to generally less evaporative conditions at those times 
(Fig. 1). Bittern salts such as sylvite and carnallite, which require a large degree of evaporation, are less common but occur in many salt basins.

The South Atlantic (Fig. 1a) and Gulf of Mexico LES comprise almost exclusively evaporites (e.g., Salvador, 1991; Davison, 2007; Gamboa et al., 2008). Existing data show that any non-evaporite interbeds are rare and confined to the proximal and/or lateral edges of the salt basins. These basins are anomalies, however, in that the vast majority of salt basins include often significant proportions of non-evaporite rocks (Fig. 1b-e), with marine or lacustrine carbonates and mudstones being the most common. Examples include LES in such disparate salt basins as the Barents Sea, the Permian Basin of Europe, the Pyrenees and Betics of Spain, the Levant Basin in the eastern Mediterranean, the Red Sea and Gulf of Suez, the Oman salt basins, the Precaspian Basin, the Kuqa Basin of China, the Flinders Ranges of Australia, La Popa Basin in Mexico, the Paradox Basin of the southwestern (SW) US, and the salt basins of Nova Scotia (e.g., Dalgarno and Johnson, 1968; Hite and Buckner, 1981; Dekker, 1985; Wade and MacLean, 1990; Lawton et al., 2001; Peters et al., 2003; Volozh et al., 2003; Chen et al., 2004; Bosworth et al., 2005; Geluk, 2007a; Feng et al., 2016; Cámara and Flinch, 2017; Flinch and Soto, 2017; Rowan and Lindsø, 2017). Siliciclastic layers can also include siltstones, sandstones, and even conglomerates (e.g., Paradox Basin; Rasmussen, 2014). Moreover, LES can contain extrusive and intrusive igneous rocks that were emplaced into the depositional salt basin (Fig. 1b), for example, in La Popa Basin, the Spanish Pyrenees, the Great Kavir Basin of Iran, and the South Oman Salt Basin (Jackson et al., 1990; Garrison and McMillan, 1999; Peters et al., 2001; Cámara and Flinch, 2017). In this paper, we use the terms salt and LES to refer to the entire stratigraphic package of evaporite and non-evaporite rocks; halite and other evaporite minerals are referred to by name.

The internal deformation of salt bodies, whether diapiric or not, can be observed in mines, in outcrop, and sometimes on modern seismic data (Fig. 2). One problem with outcrop data is that most surface exposures of salt comprise caprock, where dissolution of the halite and bittern salts has modified the original internal structure (Fig. 2a). Exposures of halite are rare, occurring in places such as Mt. Sedom diapir in Israel (Fig. 2b), the Zagros Mountains of Iran, and the Kuqa Basin of China (e.g., Talbot, 1998; Li et al., 2014; Alsop et al., 2015). Mines that target halite or bittern salts provide data beneath the caprock but are limited by the network of mine workings. Detailed maps and cross sections from mines in, among other places, the Southern Permian Basin of northern Europe (e.g., Richter-Bernburg, 1980; Schachl, 1987; Burliga, 1996; Bornemann et al., 2003) depict the complex large-scale geometries (Fig. 2c), and cut faces often show beautiful examples of small- to mesoscale deformation (Fig. 2d). Modern seismic data, especially 3-D depth-migrated data (e.g., Gamboa et al., 2008; Van Gent et al., 2011; Fiduk and Rowan, 2012; Cartwright et al., 2012;
Strozyk et al., 2012, 2014; Gvirtzman et al., 2013; Jackson et al., 2014, 2015; Raith et al., 2016; Feng and Reshef, 2016; Feng et al., 2016), can reveal the full three-dimensional geometry but lack the resolution to image the small-scale structure, especially in ductile lithologies (Fig. 2e).

Studies of observed intrasalt deformation can be supplemented by the results of both analog and numerical models (e.g., Koyi, 2001; Cartwright et al., 2012; Albertz and Ings, 2012; Li et al., 2012a; Dooley et al., 2015). These models, although limited by the materials or properties used and the imposed boundary conditions, can demonstrate the effects of varying individual parameters in simplified setups. As such, they provide significant help in evaluating and understanding natural systems.

The most common features within deformed salt bodies are folds, with varying styles and orientations, and isolated blocks of more competent rocks known as stringers. Although there are numerous published examples of intrasalt deformation, there have been few attempts to distinguish between the processes and geometries characteristic of different styles of salt tectonics. In other words, do structures such as salt-cored anticlines, passive diapirs, and salt glaciers display different styles of internal deformation? Jackson and Hudec (2017) discuss intrasalt deformation in autochthonous structures, steep diapirs, and allochthonous sheets, but their primary focus is on folds associated with flow of viscous halite. Relatively minor attention is paid to the deformation of competent layers.

In this paper, we focus on the more competent nonhalite/bittern components of the LES, investigating the internal deformation in different endmember scenarios. Specifically, we discuss the intrasalt processes and resulting geometries formed during simple extension, contraction, differential loading, and passive diapirism (including allochthonous sheets). Our primary emphasis is on the role of competency contrasts and consequent differences in the mechanics of deformation, not on any associated density contrasts. Moreover, we address only those non-halite/bittern rocks that formed part of the depositional LES; we do not include younger material that may have been entrained into salt at a later time, such as post-salt igneous intrusions or encased minibasins and salt-sheet carapace along sutures in salt canopies. Nor do we address the deformation commonly observed in outcrop due to the modification of original fabrics by dissolution. Our approach is to some degree conceptual but is founded upon observations of real structures, the results of analog and numerical models, and a thorough understanding of the underlying mechanics. Note that we discuss only those non-halite layers that are thick and strong enough to form independent mechanical units; very thin beds of anhydrite or shale tend to behave mechanically with the encasing halite, as seen within mines in the Cardona diapir of Spain or the Wieliczka diapir of Poland.

This analysis of intrasalt deformation is relevant to anyone concerned with the interiors of salt bodies. This includes, of 

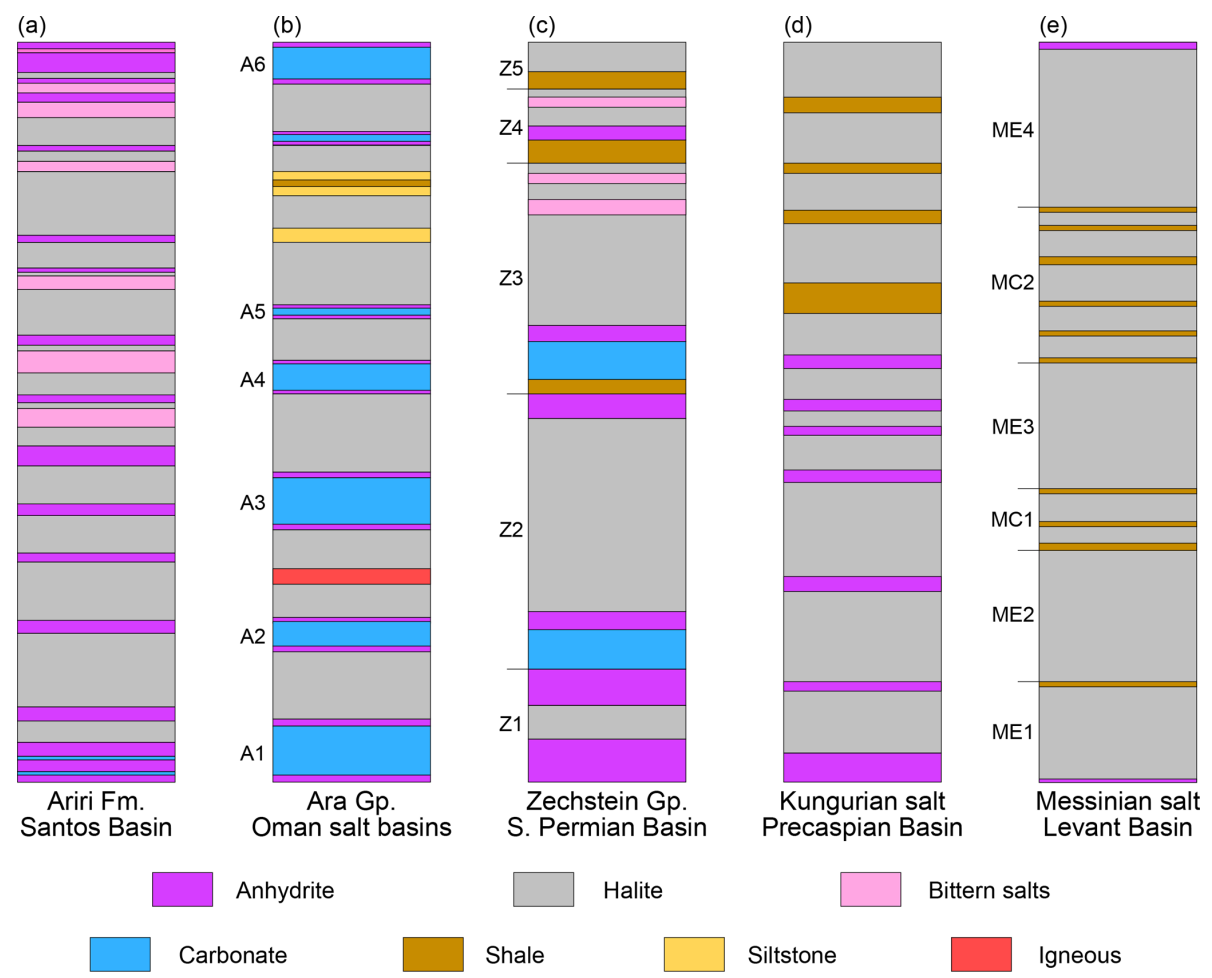

Figure 1. Representative stratigraphic columns through LESs: (a) upper Aptian Ariri Fm. from the offshore Santos Basin, Brazil (adapted from Gamboa et al., 2008); (b) uppermost Precambrian to Lower Cambrian Ara Gp. from the onshore Oman salt basins (adapted from Peters et al., 2003); (c) Upper Permian Zechstein Gp. from the Dutch sector of the Southern Permian Basin (adapted from Van Adrichem Boogaert and Kouwe, 1994); (d) Lower to Middle Permian Kungurian salt from the central portion of the Precaspian Basin, Kazakhstan (adapted from Gralla and Marsky, 2000); (e) uppermost Miocene Messinian evaporites from the Levant Basin, eastern Mediterranean (adapted from Feng et al., 2016, and Alexandros Konstantinou, personal communication, 2019) Although lateral variations in stratigraphy exist in every example, they are not shown here due to the difficulty of chronostratigraphic correlations in evaporite sequences (see Warren, 2016). Sections in panels (a) and (e) are from wells, whereas the others are more schematic; thicknesses and age spans are not equivalent in the different examples. Labels on the sides of panels (b), (c), and (e) are intrasalt stratal packages defined in the literature and referred to in the text and figures.

course, those extracting any resources (halite, bittern salts, metals, or hydrocarbons) from within salt, those drilling through salt in the search for hydrocarbons, and those looking to store materials (hydrocarbons, $\mathrm{CO}_{2}$, nuclear waste) within diapirs. The internal geometries impact the building of velocity models for depth migrations, the transmission of acoustic energy through salt, and the interpretation of the resulting images (e.g., Jones and Davison, 2014). Potential drilling problems include creep of the more mobile halite and especially bittern salts, washouts and loss of circulation, and kicks due to overpressure in stringers or fluid pockets (e.g., Kukla et al., 2011; Strozyk, 2017). A better understanding of the internal structure in different settings will help to reduce risk.

In the following sections, we first summarize relevant aspects of the rheology, then address intrasalt deformation in simple extension, contraction, differential loading, and passive diapirism. In each case, we illustrate the concepts with a combination of schematic diagrams, seismic images, and nu- merical/analog models. We then discuss complications such as the definition of the top and base of the LES, the roles of competent-layer properties such as thickness and density, and the mechanical stratigraphy of LES multilayers. Furthermore, because many or most salt structures experience combinations of the simple endmember processes, either simultaneously or consecutively, we describe and evaluate several real examples with histories that vary either spatially or temporally. Despite the possible complexities, however, we argue that there are fundamental differences in style that can be used to help distinguish between different modes of salt tectonics. Finally, we elaborate on some of the practical implications for seismic imaging, seismic interpretation, and drilling into and through salt.

\section{Rheology}

The rheology of an LES is strongly layered, with contrasts in effective viscosity of up to 5 orders of magnitude. Here, 


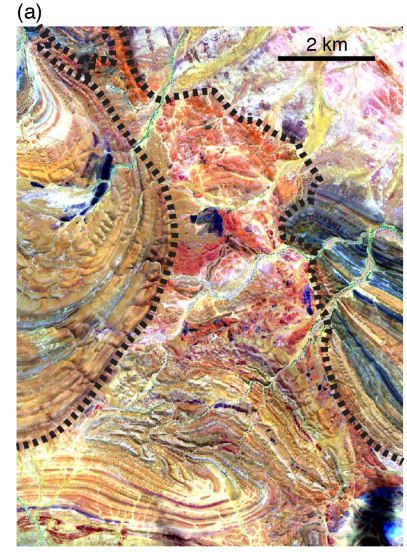

(d)

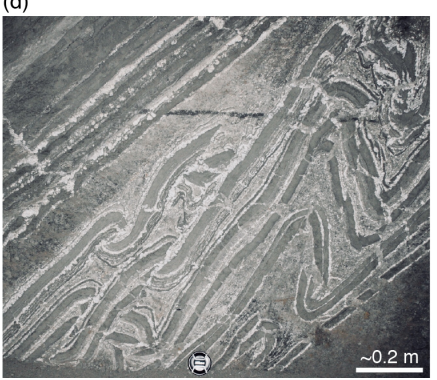

(b)
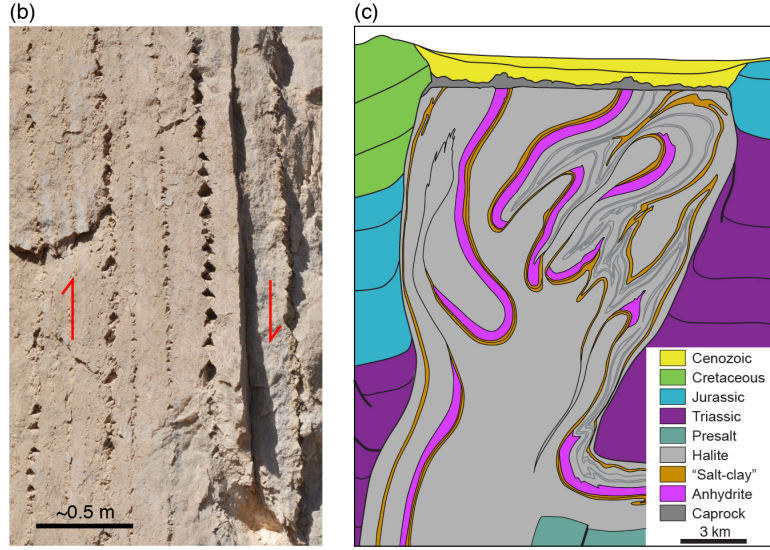

(e)

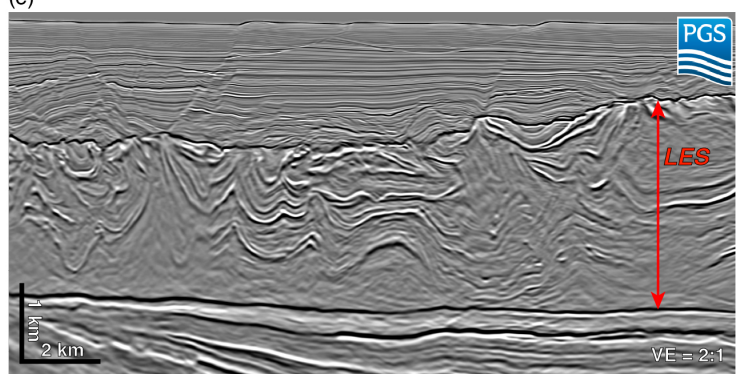

Figure 2. Examples of intrasalt deformation. (a) HyMap image with oblique cross-sectional view of exposed Witchelina diapir in the Willouran Ranges, South Australia; black dotted line marks the edge of the diapir, which has randomly oriented stringers of carbonates, siliciclastics, and volcanics in its upper half and a large stringer with recumbent isoclinal folds in the lower half (adapted from Hearon et al., 2015). (b) Photo of exposed Mt. Sedom diapir in Israel showing vertical beds of halite with bedding-parallel trains of boudins of eroded-out marls showing clockwise rotation and the indicated sense of shear (see Alsop et al., 2015). (c) Cross section of a diapir in northern Germany constrained by subsurface mine data, showing boudins of anhydrite (purple) entrained in complexly folded halite (adapted from Jackson and Hudec, 2017, itself after Hofrichter, 1980). (d) Photograph of tunnel wall in the Wieliczka salt mine, southern Poland, showing anhydritemudstone boudins (medium grey) thrusted and folded within halite matrix (see Krzywiec et al., 2018). (e) 3-D depth-migrated seismic profile (vertical exaggeration $2: 1$ ) from the Santos Basin, Brazil, with complex internal deformation shown by layered halite, anhydrite, and bittern salts (data courtesy of PGS Investigação Petrolifera Limitada).

we summarize the rheology of halite, bittern salts, anhydrite, and non-evaporite layers.

\subsection{Halite}

Halite, or rocksalt, is weak and ductile under most conditions of geologic deformation; natural fractures only form either close to the surface, as in the Mt. Sedom diapir of Israel, or when penetrated by fluids with pressures higher than the minimum principle stress in the salt. Experimentally derived flow laws have been extrapolated to the much lower strain rates of nature based on studies of the microscale deformation mechanisms operating under these conditions (see reviews by Carter and Hansen, 1983; Albrecht et al., 1990; Urai et al., 2008). Microstructural studies of naturally deformed halite show that dislocation glide and dislocation creep processes, solution-precipitation creep, and water-assisted dynamic recrystallization are all of major importance (Urai et al., 1986; Spiers and Carter, 1998; Schléder and Urai, 2005, 2007), with the relative importance varying as a function of grain size, impurity content, stress path, temperature, and fluid chemistry. During fluid-assisted dynamic recrystallization of rocksalt in nature (water content $>10 \mathrm{ppm}$ ), the grain size adjusts itself so that the material deforms close to the boundary between the dislocation-creep and pressure-solution creep fields (Fig. 3a; Spiers and Carter, 1998). Power-law flow is thus proposed to be a good representation of this behavior. Differential stress in naturally deforming rocksalt (Fig. 3a) generally ranges between 0.5 and $2 \mathrm{MPa}$ but can be as high as $5 \mathrm{MPa}$ at shallow levels (Spiers and Carter, 1998; Schléder and Urai, 2005, 2007); grain size is typically around $10 \mathrm{~mm}$ in diapiric halite and effective viscosities at these differential stresses are between $10^{18}$ and $10^{19} \mathrm{Pas}$.

\subsubsection{Other evaporites}

Bittern salts such as carnallite and bischofite deform in a manner similar to that of halite but are significantly weaker than rocksalt (Urai, 1983, 1985; Urai et al., 1986). In general, bittern salts have effective viscosities 100 to 1000 times 
(a)

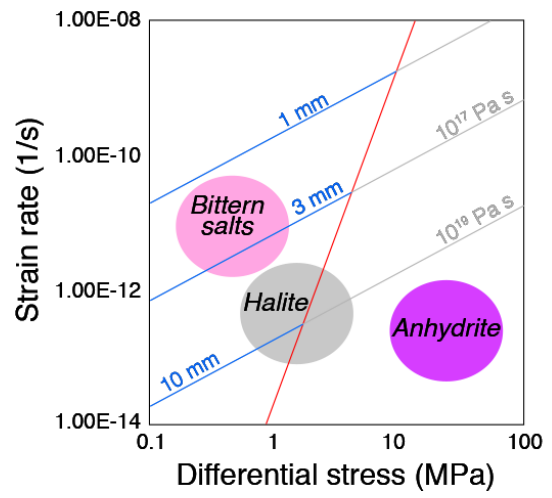

(b)

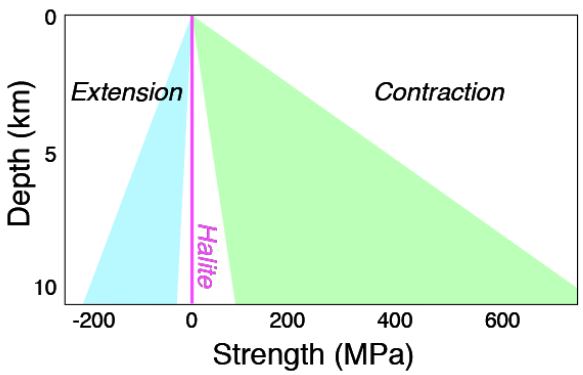

Figure 3. (a) Stress-strain rate diagram at a temperature of $60^{\circ} \mathrm{C}$ illustrating the most likely conditions for evaporite deformation addressed in this paper. The grey lines represent different halite viscosities, the red line is an extrapolation of laboratory data for dislocation creep of halite, and the blue lines are the flow lines for pressure-solution creep for different grain sizes. The intersections of the blue lines with the red line represent steady-state flow where the grain size is in equilibrium with the differential stress. Thus, the grey ellipse is an estimate of the stress and strain rate conditions for the flow of halite in the subsurface, constrained by measurement of the differential stress by subgrain-size piezometry. The purple ellipse is an estimate of the conditions for anhydrite deformation during layer-parallel shortening based on analysis of fold shapes, and the pink ellipse is an estimate of the condition for bittern salts. (b) Schematic diagram comparing the strength of halite and non-evaporite rocks as a function of depth in extension and contraction (adopted from Weijermars et al., 1993, and Jackson and Hudec, 2017). The purple line is for wet halite, which has a constant, very low strength $(<1 \mathrm{MPa})$; the colored fields are for non-evaporite rocks in extension (blue) and contraction (green), which range from dolostones (very strong) to highly overpressured mudstones (very weak).

lower than that of halite and thus flow 100 to 1000 times faster than halite under a given differential stress (Fig. 3a). When present, they form the weakest layers of the LES.

The rheology of anhydrite in the subsurface is not well constrained by extrapolation from laboratory experiments, probably because solution-deposition processes are much more important in nature. In shortening, anhydrite behaves as a viscous material, but the shape of concentrically folded anhydrite layers within halite indicates an effective viscosity 10-100 times that of rocksalt (Fig. 3a; Schmalholz and Urai, 2014). In layer-parallel extension, however, anhydrite behaves in a brittle manner, readily deforming by boudinage with variable degrees of pinch-and-swell structures prior to eventual rupture. High pore pressures sustained by the surrounding impermeable rocksalt may impact how deformation is accommodated (Van Gent et al., 2011), and anhydrite weakens markedly at higher temperatures (Jackson and Hudec, 2017).

\subsubsection{Non-evaporite layers}

Whereas there is strong evidence for anhydrite being viscous under layer-parallel shortening and geological strain rates, other strong interbeds such as carbonates, mudstones, and sandstones are materials deforming according to frictionalplastic constitutive laws. There can be a large range of strength depending on the lithology, the burial and diagenetic history and consequent degree of cementation, and the amount of overpressure sealed by of the surrounding halite. Nevertheless, these interbeds are typically consid- erably stronger than the rocksalt (Fig. 3b). In addition, frictional-plastic materials are significantly weaker during extension than they are during contraction, failing earlier (and again, in a brittle manner) during extension (Fig. 3b).

\subsection{LES rheology}

As a package, the bulk rheology of an LES will vary between the Voigt and Reuss bounds (homogeneous strain and homogeneous stress, respectively; see Hill, 1952) and is strongly anisotropic: it is weakest in bedding-parallel simple shear and strongest in bedding-parallel horizontal shortening. However, these endmembers are rarely applicable to the complex kinematics and geometries of salt deformation, leading to folding, boudinage of the competent layers, and bedding-parallel shear that enhances multilayer folding. At high strains, the LES forms a tectonic melange which is less anisotropic and stronger than pure rocksalt.

\section{Modes of salt tectonics}

\subsection{Extension}

Competent layers encased within a weak, ductile matrix undergo boudinage during layer-parallel extension (e.g., Ramberg, 1955; Ramsay, 1967; Goscombe et al., 2004). With enough extension, the strong layers separate into distinct boudins, with the ductile material flowing into the space created. In metamorphic rocks, length-to-thickness aspect ratios typically range from 2 to 4 (Fossen, 2010). 

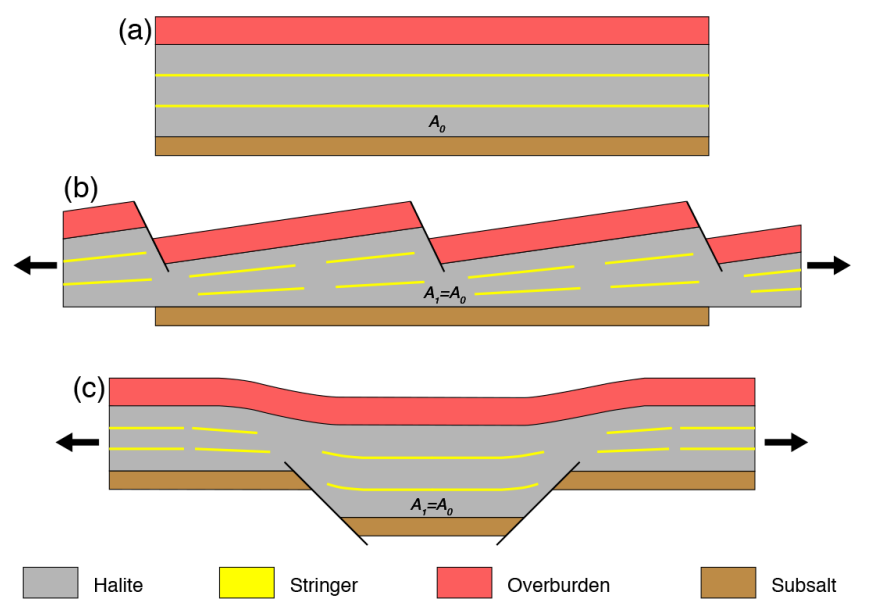

Figure 4. Conceptual diagrams of layer-parallel extension: (a) undeformed salt layer (of area $A_{0}$ ) with two competent internal beds (yellow); (b) boudinage of competent beds into stringers during thin-skinned extension, assuming the primary décollement is near the base of salt; (c) boudinage during thick-skinned extension, concentrated in areas of drape folds over pre-salt faults.

When formed by layer-parallel extension in salt, the boudins are termed stringers (Mattes and Conway Morris, 1990). During thin-skinned extension, the overburden extends by the development of normal faults that may have a preferred dip direction or may form conjugate sets. The faults detach within the salt, presumably in zones of concentrated shear, while intrasalt strong layers form boudins that are distributed throughout the region where suprasalt extension occurs (Fig. 4b). If extension is thick-skinned, boudinage is likely to be concentrated in areas of drape folding above presalt faults (Fig. 4c). Interestingly, intrasalt stringers have significantly larger length-to-thickness ratios compared to those in metamorphic rocks (Burliga, 1996; Van Gent et al., 2011).

An analog model of gravity-driven thin-skinned extension shows some characteristics that may occur in nature. Intrasalt strong layers are extended 3-4 times as much as the cover, with the amount of stretching increasing downward (Fig. 5a). This is due to the significant thinning and attenuation of the weak and ductile model material, with bulk basinward flow during translation of the overburden - a combination of pure shear and simple shear (Brun and Mauduit, 2009). Although this internal strain variation cannot be seen in the tectonically driven thick-skinned example of Fig. 5c, the intrasalt strong layer is more extended than the cover (where the extension is off the end of the line) or the pre-salt section. With increasing extension, the cusps in the top salt created by suprasalt normal faults (Fig. 4b) evolve into isolated, triangular remnants termed salt rollers. These have more complex internal deformation (Brun and Mauduit, 2009), as recorded by the internal layering of the Santos Basin LES within a large salt roller (Fig. 5b).
The models of Fig. 4 are plane strain, but if movement of the salt is divergent, more complex patterns arise (Abe et al., 2013). This might happen above a radially spreading allochthonous salt canopy (Rowan et al., 1999) or deltaic lobe (Gaullier and Vendeville, 2005). Alternatively, drape folding from a common footwall to two pre-salt faults with different trends can lead to multidirectional extension (see Dooley et al., 2004), and crustal doming may cause outwardly directed gravity gliding and the development of a polygonal pattern of extension, as suggested for the pods and interpods of the central North Sea (Karlo et al., 2014). Whatever the drive, non-uniaxial extension leads to tablet boudinage in which intrasalt strong layers are broken in multiple directions (e.g., Wegmann, 1932; Zulauf et al., 2011).

\subsection{Contraction}

The dominant structural style of contraction above a salt layer is that of detachment folds cored by the mobile salt. During early stages of shortening, the area in the core increases as the fold grows (Dahlstrom, 1990; Stewart, 1999); this is balanced in a two-dimensional analysis by sinking of synclines, with underlying salt flowing laterally into the anticlines (Fig. 6). Because rocks are generally stronger in shortening than in extension, the competent intrasalt layers tend to remain coherent and unbroken, at least at relatively low strain. When the strong layers are continuous, again in a plane-strain model, the intervening areas of viscous salt maintain their area. Internal strong layers would thus seem to have progressively less length downward because the uppermost part of the LES experiences similar amounts of shortening to the cover, while the lowermost part is almost undeformed (Fig. 6b). In order to maintain bed length, therefore, the competent layers form fold trains or thrusts with increasing amounts of shortening toward the base of the salt (Fig. 6c). The deformation is commonly disharmonic or polyharmonic, with fold wavelengths dependent on layer thickness and strength, and folding is accommodated primarily by layer-parallel slip. As contractional strain increases over time, the strong layers may get disrupted, especially beneath synclines and in the cores of anticlines, potentially leading to mixing of different halite-rich portions of the LES and thus more complex deformation.

Experimental models with strong intra-polymer layers display some of these expected features (Fig. 7a, b). The layers generally form complex folds that are generally tight to isoclinal, range from upright to recumbent, and are commonly ptygmatic. They may verge in either direction due to overall flow of ductile material from beneath synclines into the cores of adjacent anticlines (Fig. 7a). The anticlinal cores are where the strong layers are most likely to be ruptured due to more intense deformation. When there are two or more competent layers, the deformation is disharmonic and the deeper layer experiences more shortening (Fig. 7b). 

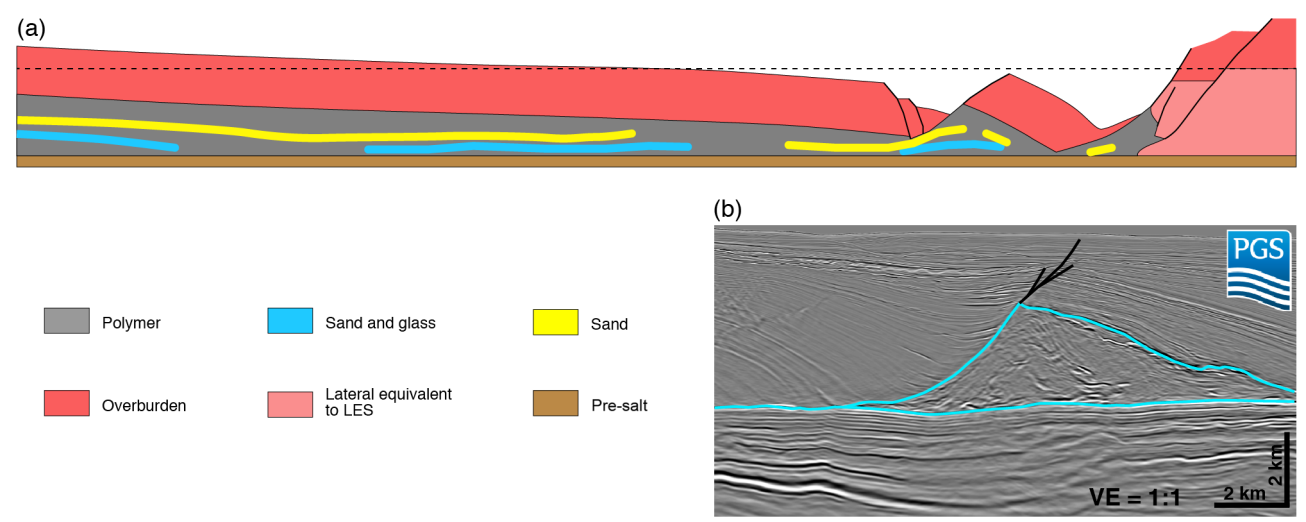

(c)

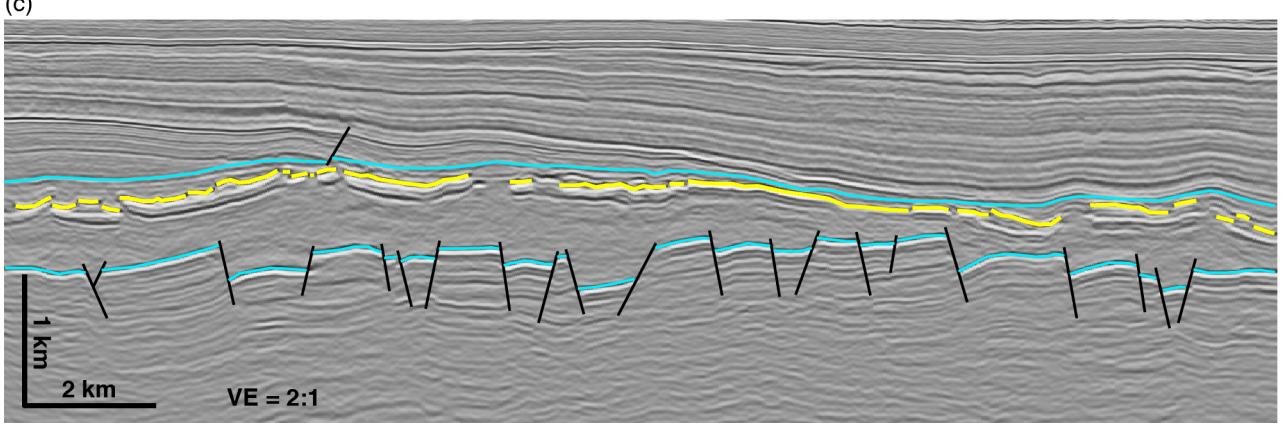

Figure 5. Examples of extension of salt with internal competent beds: (a) simplified results of analog model in which the polymer layer was thinned and attenuated during thin-skinned extension - the black dashed line shows the original top polymer, and the yellow and blue layers are stronger intra-polymer layers that separated into boudins, with more extension at the deeper, blue level (adapted from Cartwright et al., 2012; model by Tim P. Dooley); (b) 3-D depth-migrated image of a large salt roller from the Santos Basin (vertical exaggeration $1: 1$ ), with very little of the internal layering seen in Fig. 2e visible here due to more disruption during extension (data courtesy of PGS Investigação Petrolifera Limitada); (c) 3-D depth-migrated seismic profile (vertical exaggeration 2:1) from the Friesland Platform of the onshore Netherlands showing the Zechstein salt (between cyan horizons) with boudins of the Z3 stringer (top of stringer in yellow) generated during thick-skinned extension (adapted from Strozyk et al., 2014).

Seismic images may or may not match the analog models. In the contractional domain of the Santos Basin, for example, there is indeed more contraction at deeper levels of the LES than at shallower levels, which fold concordantly with the overburden (Fig. 7c). In the Levant Basin, however, shallower strong layers appear to have greater amounts of shortening (Fig. 7d). This is probably due to the dominance of Couette flow (simple shear) in the Messinian evaporites (see Fig. 8a), as recorded by fluid escape pipes within the salt and its overburden (Cartwright et al., 2018).

Although Couette flow is nicely illustrated in the Levant Basin, other shear profiles are possible (Fig. 8). These may include intrasalt basal shear, intrasalt basal shear with reverse Couette flow, and asymmetric Poiseuille flow. Intrasalt basal shear seems to be important in the Santos Basin, with the intrasalt beds shortened above the unaffected pre-salt section; so why is this different from what is observed in the Levant Basin? The key may lie in the larger-scale geometry of the LES and thus an evolving internal shear profile over time. When the salt layer is broadly tabular, with roughly parallel top and base (i.e., early in the deformation, as in the Levant Basin), Couette flow may dominate (Fig. 9a). As folds amplify with greater amounts of shortening, the zone of shear becomes increasingly concentrated beneath synclines (Fig. 9b), ultimately leading to a narrow shear zone along the thin remnant salt in these locations and thus most likely near the base of salt even beneath the anticlines (Fig. 9c).

The schematic models of Figs. 6, 8, and 9 have relatively little bedding-parallel shortening. As the amount of contractional strain increases, intrasalt deformation is likely to get more complex in several ways. First, compression may lead to increased fluid pressures in siliciclastic or carbonate layers and, consequently, in situ hydraulic fracturing, as suggested for the Katanga Copperbelt (Cailteux et al., 2018). Second, strong layers may become disrupted beneath synclines, as seen on the left side of Fig. 7a, with increased amounts of folding and disruption in the anticlines due to lateral salt flow. Thus, deeper strong layers, which may experience greater magnitudes of deformation, will often be more transparent in fold cores (e.g., see Fiduk and Rowan, 2012, Fig. 5, or Jackson et al., 2015, Figs. 6 and 7). Third, as the salt-cored anticlines tighten over time, the cross-sectional 
(a)
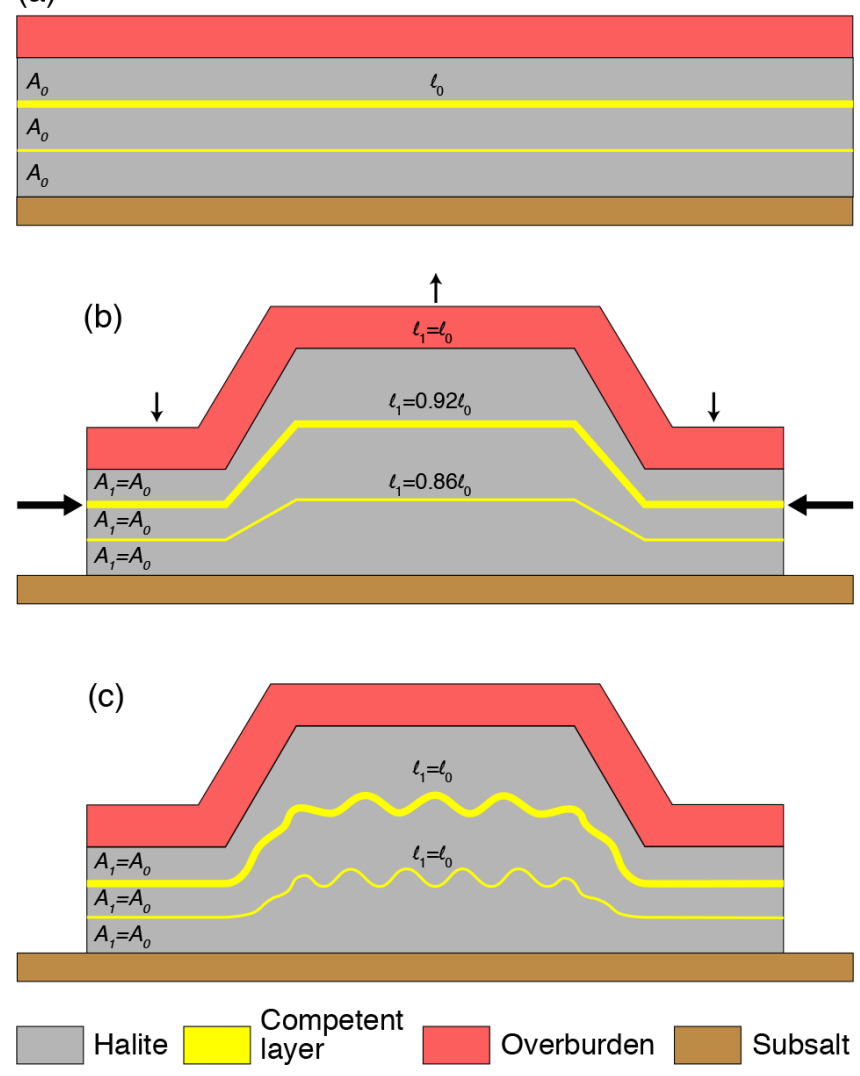

Figure 6. Conceptual diagrams of plane-strain layer-parallel shortening: (a) undeformed salt layer with two competent internal beds (yellow), with different thicknesses and of length $l_{0}$, that divide the halite into three layers with equal area $A_{0}$; (b) shortening of $14 \%$ generates folded overburden (box fold for simplification), with thickening of salt in core of anticline and thinning beneath synclines; maintaining halite areas, with no breaking or folding of the strong beds, results in apparent decrease in line length of the competent beds; (c) more realistic scenario of buckle folds in competent beds, with the amount of internal shortening increasing downward to maintain bed length - note the longer wavelength in the thicker strong layer.

area in the core, which initially increases, begins to decrease until the limbs are roughly parallel (Dahlstrom, 1990; Stewart, 1999). This expels salt, which probably flows along strike into those parts of the anticline that are still in relatively immature, area-increasing phases of shortening, thereby creating a greater likelihood of competent-layer disruption in three dimensions. Fourth, thrust faults may develop in the cover with increased amounts or rates of shortening (or due to the salt budget; Stewart, 1999), also leading to increased rupturing of intrasalt strong layers (e.g., Fig. 7a).

\subsection{Differential loading}

In a sense, the internal deformation generated by differential loading is similar to that typifying contraction: salt moves lat- erally from areas where it is being thinned to areas of thickening. In differential loading, the synclines and anticlines of shortening are replaced by withdrawal basins and salt pillows. The key difference, however, is that in differential loading, there is no net shortening of the salt and its cover, which leads to a rather different internal deformation style.

In plane strain, salt deflation beneath overlying depocenters is effectively pure-shear vertical flattening, while the corresponding inflation of salt pillows comprises convergent flow and intrasalt shortening. Thus, intrasalt strong layers form boudins beneath depocenters but are folded within pillows (Fig. 10), with no net change in bed length. If there is little to no mixing of ductile material from above and below each competent layer, shallower layers exhibit more strain because there is progressively less vertical displacement in the salt with increasing depth (Fig. 10c). With more deformation, of course, the internal deformation becomes more complex than in the simple models shown (see also the model derived from the Oman diapirs in Reuning et al., 2009).

Two-dimensional numerical models with a single intrasalt competent layer illustrate the geometries that develop during differential loading. In a symmetric scenario, salt flows into the pillow from both directions, generating boudinage and folding or, in effect, convergent intrasalt linked extension and contraction (Fig. 11a). In an asymmetric model of loading only from one direction, with ultimately much greater amounts of net salt movement, the competent layer is almost completely absent beneath the depocenter, and initial folding leads eventually to complexly disrupted geometries with vertical repetition of stringers (Fig. 11b). An example from the northern Netherlands shows that the Z3 anhydrite/carbonate/shale layer of the Zechstein salt (Fig. 1c) forms boudins (stringers) beneath minor depocenters but is more continuous and folded within the intervening salt pillow (Fig. 11c).

In the case of linear bodies of inflated salt, the twodimensional analysis of Fig. 10 is a reasonable approximation of salt flow for all but the ends of the salt ridge. However, for circular to elliptical pillows (or diapirs), intrasalt deformation is more complex due to convergent flow and consequent constrictional strain (Van Gent et al., 2011). Thus, whereas deeper flanks are characterized by boudinage on dip lines and folding on strike lines, folds are likely to dominate on lines of any orientation over higher parts of the pillow (Fig. 12).

\subsection{Passive diapirs}

Passive diapirs, which are those that grow at or just beneath the ground surface or seafloor as sediment is deposited, may be triggered by various means: extension (reactive diapirism of Vendeville and Jackson, 1992), contraction (especially if the roof is thinned by erosion; Coward and Stewart, 1995), or differential loading (e.g., Ge et al., 1997). These early processes, of course, will cause deformation of intrasalt strong 

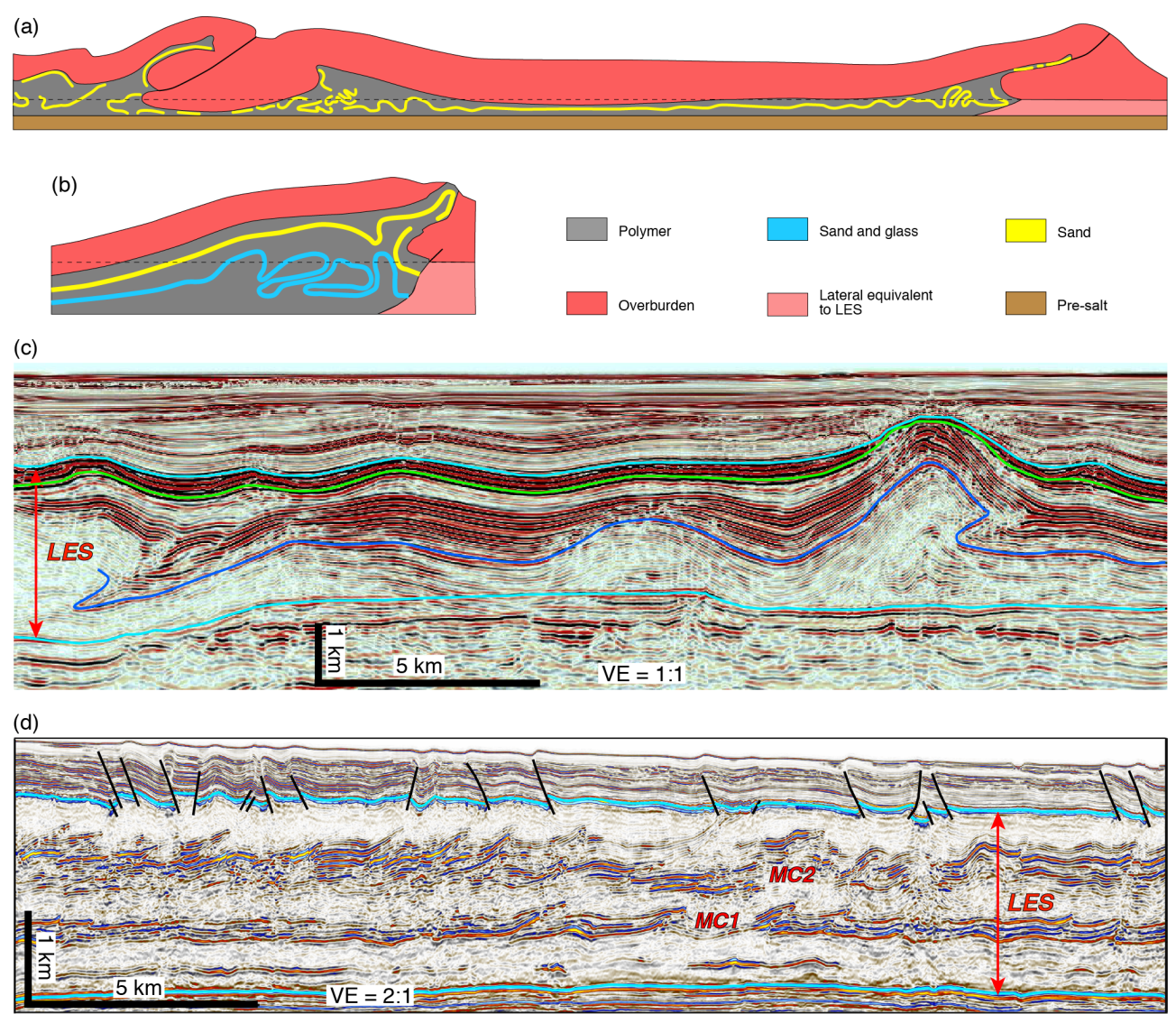

Figure 7. Examples of layer-parallel shortening of salt with internal competent beds: (a) simplified results of analog model of shortening detached on polymer layer with a thin interbed of competent sand (yellow) located at the middle level of the polymer - the black dashed line shows the original top polymer, and the intra-polymer layer forms tight to isoclinal folds that have been partially disrupted (adapted from Pla et al., 2019); (b) simplified results of analog model showing shortened and inflated polymer (this is the other half, but reversed, of the model shown in Fig. 4a) - the black dashed line shows the original top polymer, and the yellow and blue layers are stronger intrapolymer layers, with more contraction at the deeper, blue level (adapted from Cartwright et al., 2012; model by Tim P. Dooley); (c) 3-D depth-migrated seismic profile from the Santos Basin (vertical exaggeration 1:1) with a gently folded LES (between the cyan horizons) and cover - the deep (blue) intrasalt level is shortened more than the shallow (green) level, but this is not due to progressive deformation during evaporite deposition (modified from Fiduk and Rowan, 2012); (d) 3-D depth-migrated seismic profile (vertical exaggeration $2: 1$ ) from the Levant Basin showing the mostly tabular Messinian evaporites (LES, between the cyan horizons) with only minor folding of the cover - the shallower MC2 intrasalt sequence (see Fig. 1e) is shortened more than the MC1 level (modified from Feng et al., 2016).

layers prior to passive diapirism, whether in the form of boudinage or folding/thrusting. However, in the analysis below, we consider the simplified scenario in which a passive diapir initiates without any precursor deformation. This may happen in nonmarine or very shallow-water depositional settings, such as the Witchelina diapir in the Willouran Ranges of South Australia, where the crest of the salt was exposed as the earliest suprasalt sediment onlapped it, so that it was a passive diapir from the onset of movement (GannawayDalton, 2019).

In such a case, the deformation is similar to that of differential loading in that the salt thins beneath minibasins and thickens in the diapir. However, the strains are much higher: whereas a salt pillow generally has a height-to-width ratio of less than 1 and low-dip salt flanks, mature passive di- apirs are typically at least several times higher than they are wide and have steeper flanks. Thus, the amount of lengthening of intrasalt strong layers is considerably greater than in salt pillows, leading to more boudinage. Note that these stringers are often entrained within larger-scale ductile folding of the halite-dominated LES (Fig. 2c) caused by constrictional strain (curtain folds; Talbot and Jackson, 1987) and differential flow and shear between the inner and outer parts of the rising diapir.

Consider a simple two-dimensional model (Fig. 13a) in which all intrasalt layers experience the same amount of lengthening (although other scenarios are possible, for example, when deeper levels are less involved in flow into the growing diapir). Extension (boudinage into stringers) will increase as the diapir grows. The extension $e$ is calculated as 
(a)

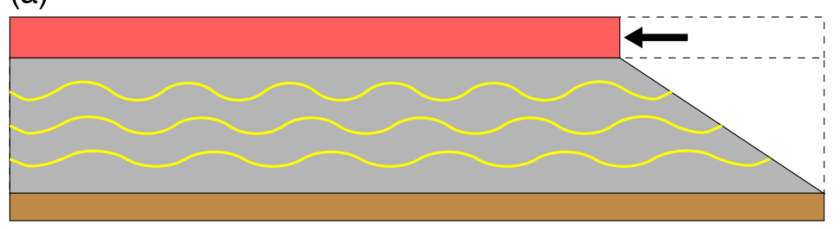

(b)

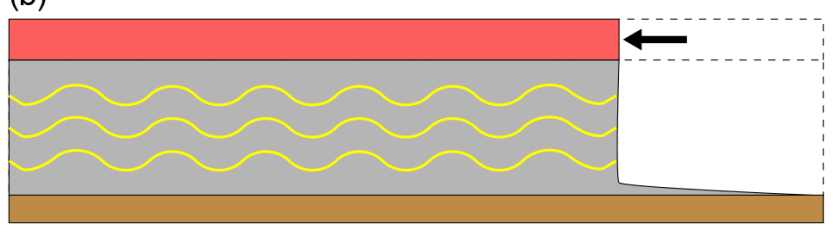

(c)

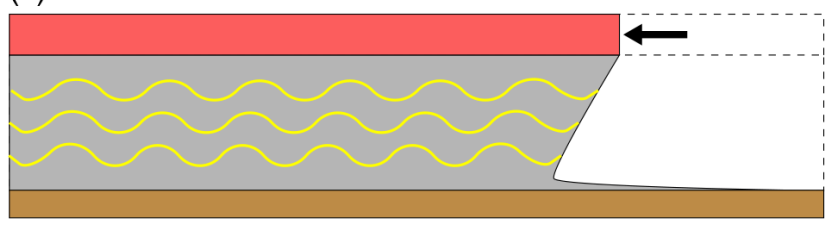

(d)
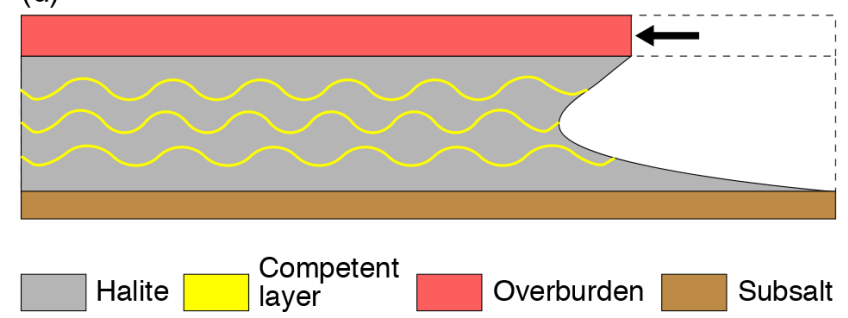

Figure 8. Different possible shear profiles during shortening (inspired by Cartwright et al., 2012), with cover deformation not shown for the sake of simplicity: (a) Couette flow (simple shear of entire salt layer), resulting in upward increasing shortening magnitudes for intrasalt competent beds; (b) intrasalt basal shear, with competent beds shortened equally; (c) combined inverse Couette flow and basal shear, with intrasalt shortening decreasing upward; (d) asymmetric Poiseuille flow (or combined Couette and Poiseuille flow), with maximum shortening of intrasalt beds near the center of the salt layer.

the change in length divided by the original length:

$e=\left(\left(l_{0}+2 h\right)-l_{0}\right) / l_{0}=2 h / l_{0}$,

where $h$ is the height of the diapir and $l_{0}$ is the original length of the strong layers that move into the diapir (Fig. 13a). If we define the aspect ratio of the diapir, $a$, as $h / w$, where $w$ is the diapir width, and the salt fetch factor, $F$, as $\left(l_{0}-w\right) / w$, i.e., the ratio between the width of the area of salt that moves into the diapir and the width of the diapir, then

$e=2 a /(F+1)$.

In other words, the lengthening of an intrasalt strong layer increases as the diapir grows (as $a$ increases) but decreases (a)

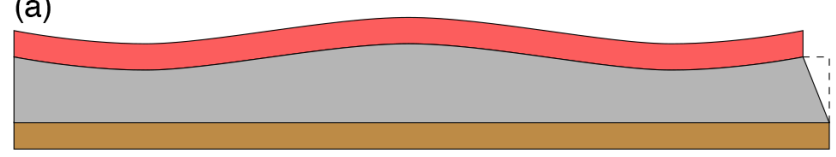

(b)

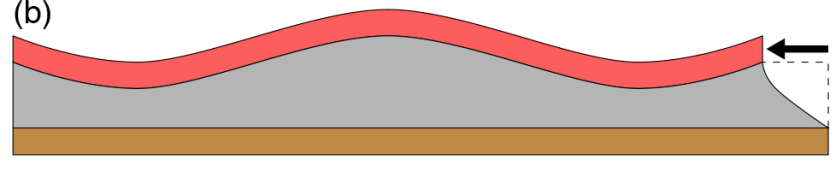

(c)

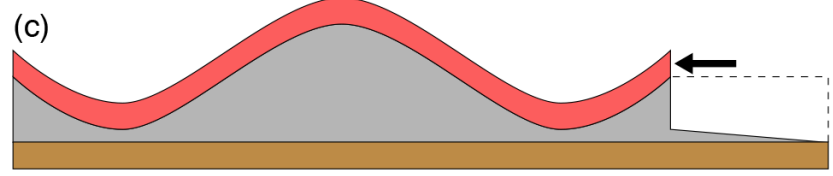

Halite

Overburden

Subsalt

Figure 9. Possible changes in intrasalt shear profile during progressive shortening and growth of contractional anticlines: (a) incipient shortening accommodated by Couette flow; (b) as synclines sink and the zone of shear becomes more concentrated, Couette flow becomes modified; (c) as the salt beneath the synclines thins, intrasalt basal shear becomes increasingly dominant. Complex intrasalt deformation in the anticlinal cores is not shown.

as the width of the area of salt that feeds the diapir increases (Fig. 13b). In general, tall diapirs fed locally experience more internal extension than short diapirs fed from a broader area.

As strong layers are broken into stringers and carried up with the ductile halite within the growing diapir, they rotate to near vertical due to shear caused by upward Poiseuille flow (Fig. 13c; see also Fig. 2c). In the Kłodawa diapir of Poland, for example, vertically oriented boudins of anhydrite, dolostone, and clays indicate at least $30 \%$ extension (Burliga, 1996), and the largest carbonate/siliciclastic boudins are rotated to vertical near the margins of Onion Creek diapir in the Paradox Basin (Hudson et al., 2017). Even in the more realistic scenarios in which stringers are entrained in ductile folds, most of the stringer occurrences are steep (Fig. 2c). Because steep stringers are difficult to image on even the best modern seismic data, passive diapirs typically appear transparent, whereas the stringers tend to be more visible where they are subhorizontal in the deep source layer (Fig. 14). We return to this topic later in the discussion section.

As already stated, and still ignoring the ductile folds, more complex strain histories than that shown in Fig. 13a are possible. Instead of the entire salt layer flowing synchronously into the growing diapir, shallower levels may move upward first, followed only later by salt from deeper levels. This has the effect of leaving younger stringers near the margin of the diapir at deeper levels, whereas older stringers will be concentrated in the center of the diapir and at shallower levels. These patterns are observed in exposed diapirs, for exam- 
(a)

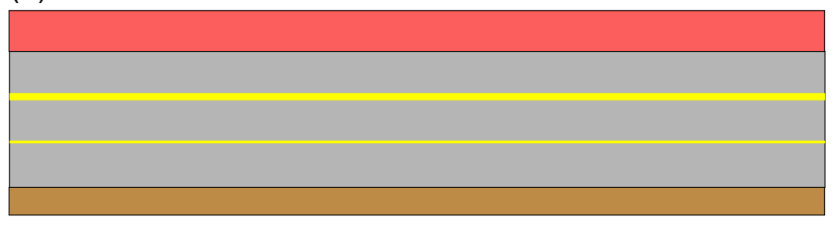

(b)
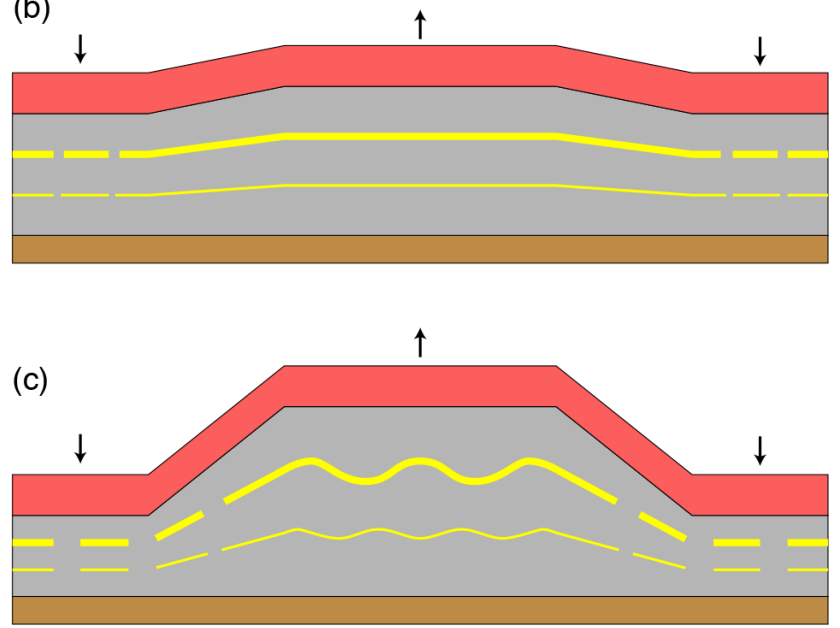

Halite Stringer Overburden Subsalt

Figure 10. Conceptual diagrams of salt inflation and deflation due to the application of a differential sedimentary load (not shown), with two-dimensional flow of salt only within the model area (salt to right and left of model flows into adjacent salt pillows): (a) undeformed salt layer with two competent internal beds of differing thickness; (b) incipient salt movement into salt pillow, with boudinage of strong layers beneath depocenters and folding within pillows; (c) further deformation of intrasalt layers due to increasing deflation/inflation, with greater amounts of strain at shallower levels if there is insignificant mixing of halite above and below each competent bed.

ple, in Iran (e.g., Jackson et al., 1990) and South Australia (Thomas E. Hearon IV, personal communication, 2014)

The development of allochthonous salt (other than sourcefed thrusts; Hudec and Jackson, 2006) is a form of passive diapirism in which the salt moves more laterally than vertically at the ground surface or just beneath the seafloor. Moreover, most salt sheets originate from steeper feeder diapirs in which the strong layers are already disrupted. With more lateral flow, stringers rotate to lower angles than in the steep diapirs during flow subparallel to the base salt. Although it might be thought that stronger, denser intrasalt layers are left behind as the more ductile halite and bittern salts flow laterally in the salt sheet, that is demonstrably not the case. Salt sheets in South Australia contain abundant stringers of carbonates, siliciclastics, and igneous rocks that can be more than $2 \mathrm{~km}$ long and hundreds of meters in thickness (see maps in Rowan et al., 2019).

\section{Discussion}

We have presented an overview of the deformation of competent intrasalt layers in different endmember modes of salt tectonics. For the sake of simplicity, the focus has been on individual competent beds, but of course there can be larger packages comprising multiple competent layers or even non-evaporite or evaporite-poor sequences within the overall LES. Moreover, we have emphasized the deformation of individual beds well within the LES; those closer to the margins (upper or lower) do not deform as readily even in strong salt flow. In the following sections, we discuss the definition of the top and base LES, the roles of layer thickness and density, the mechanical stratigraphy of multilayers, and spatial or temporal variations in the operative mode of deformation.

\subsection{Definition of LES}

The mobile portion of an evaporite sequence does not necessarily represent the entire LES. In many cases, the base of the evaporites is dominated by interbedded anhydrite and carbonate or siliciclastics, with no or little halite or bittern salts (e.g., the Santos and Oman salt layers; Fig. 1a, b), due to the gradual and cyclical onset of evaporative conditions. These stronger margins may or may not be involved in the deformation. If they are, the deformation may be spatially variable, so that on seismic data, the base of transparent salt appears to cut up and down section (Fig. 15). Where the base is shallower, it is underlain by an in-place package of typically bright reflectors (dominated by anhydrite with carbonates/siliciclastics, depending on the salt basin); where the base of the mobile salt is deeper, the bright package is absent. Isolated stringers near the base of salt are interpreted to represent the same basal package where it has been incorporated into the mobile salt. In addition, the transparent areas likely contain stringers that are too small or steep to be imaged.

One consequence of stronger basal layers in the LES is that even after the mobile portion is removed, for example, by flow from beneath a minibasin into a flanking diapir, evaporites may remain along the resultant weld. In the Santos Basin, a well encountered $22 \mathrm{~m}$ of anhydrite, carbonate, and sandstone along a seismically defined weld (Jackson et al., 2014), and 31 out of 41 wells that penetrated thin salt $(<100 \mathrm{~m}$ thick) in the Campos Basin encountered only anhydrite (Wagner and Jackson, 2011). A common interpretation is that these represent broken-up blocks of less mobile material trapped along the weld due to boundary drag effects as the salt thinned. We suggest as an alternative that at least some of these represent the basal portions of the LES that were never broken up in the first place and thus remain stratigraphically in place.

The tops of some LES may also have a relatively thin anhydrite- and/or carbonate-dominated section (Fig. 1a, b) that may or may not be involved in the deformation. In 
(a)

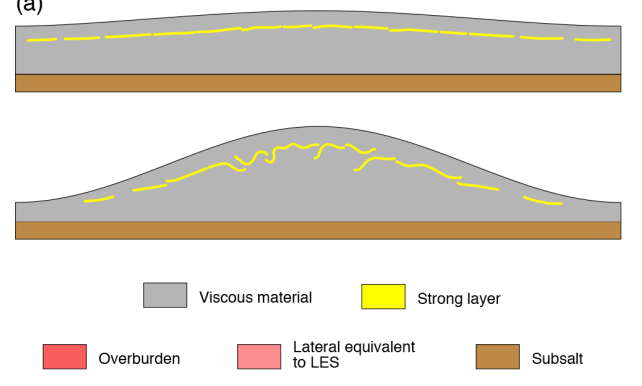

(b)
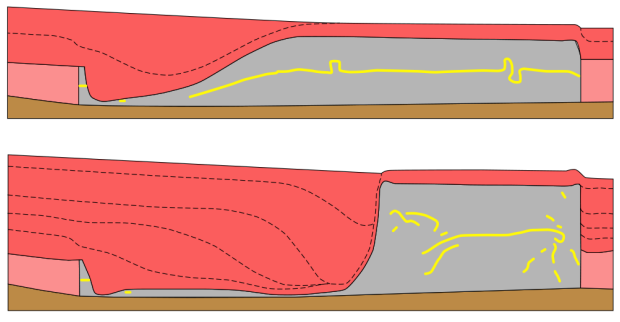

(c)

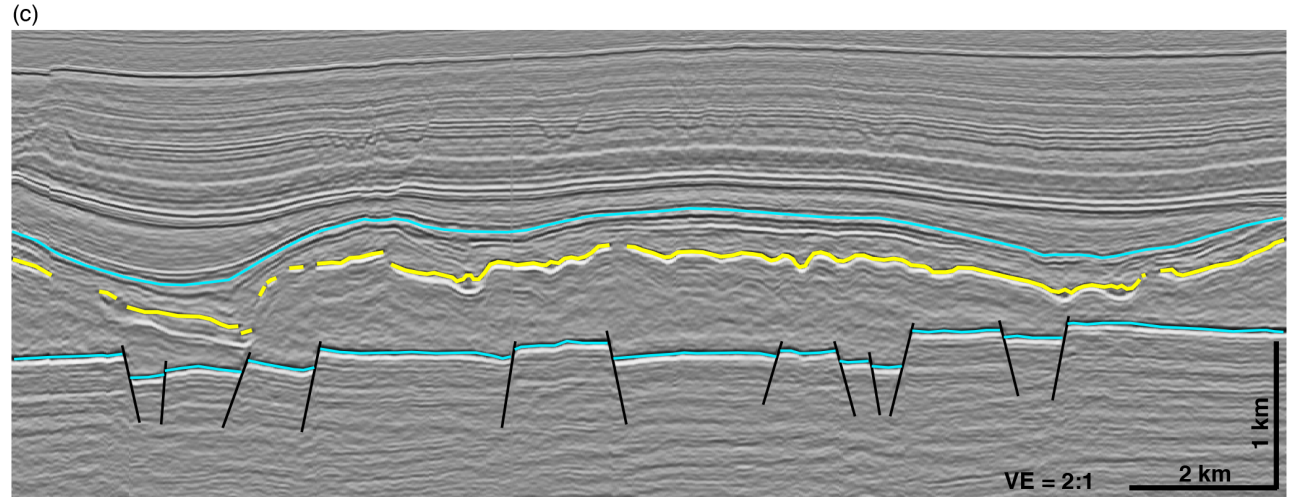

Figure 11. Examples of differential loading of salt with internal competent beds (yellow): (a) simplified sequential results of finite-element model with subsidence on both ends and inflation of a central salt pillow - the early deformation of the strong layer (top) is dominated by boudinage, but further deformation leads to folding and overlap of the boudins in the pillow (adapted from Raith, 2017); (b) simplified sequential results of numerical model with progradational loading (indicated by black dashed lines) and consequent inflation - the strong layer is pulled almost completely apart beneath the depocenter and is first folded and then thrusted and disrupted in the inflated body (adapted from Albertz and Ings, 2012); (c) 3-D depth-migrated seismic profile (vertical exaggeration 2:1) from the Groningen High of the onshore Netherlands showing a gentle salt pillow of the Zechstein salt (between cyan horizons) between two Triassic depocenters - the Z3 stringer (yellow) is mostly continuous and slightly folded within the pillow but more broken up beneath the depocenters (adapted from Strozyk et al., 2014).

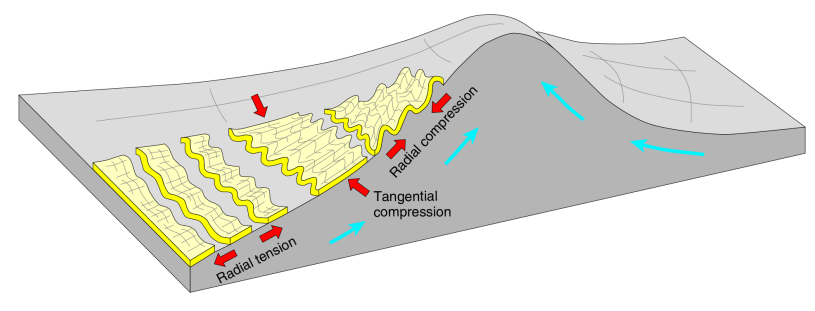

Figure 12. Schematic diagram of three-dimensional stress (red arrows) and associated deformation of an intrasalt competent layer (yellow) in a circular to slightly elliptical salt pillow. As salt flows from beneath the depocenters into the pillow (blue arrows), radial extension and contraction (boudinage and folds) are accompanied by constrictional folding due to convergent flow into the pillow. Drafted from original sketch by Frank J. Peel.

other basins, there can be thicker sequences of siliciclastics and/or carbonates interbedded with variable amounts of evaporites overlying a more halite-rich salt layer. In the Red Sea salt basin, for example, the Mansiyah/South Gharib salt is overlain by the Ghawwas/Zeit formations. In the proximal Midyan area of Saudi Arabia (adjacent to the NE Red
Sea), the Ghawwas Formation comprises mostly siliciclastics with thin anhydrites (Hughes and Johnson, 2005) and clearly forms the brittle overburden to the ductile Mansiyah salt (see seismic profiles in Tubbs et al., 2014). Farther basinward, however, the relative proportion of siliciclastics in the Ghawwas Formation decreases, and there are increasing amounts of interbedded halite (Krzysztof Sliz, personal communication, 2018). Here, the Ghawwas Formation deforms with the Mansiyah salt as part of the mobile LES, with variable amounts of deformation including recumbent, isoclinal folds similar to those observed in the Santos Basin (Rowan, 2014, Fig. 9a). Thus, the top of the mobile LES shifts stratigraphically up-section from proximal to distal regions.

Another example is provided by the Precaspian Basin. The main Kungurian salt (Fig. 1d) is overlain by Ufimian and Kazanian interbedded siliciclastics and halite, with the combined package considered by some as the LES (Gralla and Marsky, 2000; Volozh et al., 2003). However, there are variable relationships: whereas both the Kungurian and Kazanian strata together form diapirs in more distal areas (Volozh et al., 2003, Fig. 5, panels B and E), the Kazanian sequence forms the brittle overburden to the ductile Kungurian salt in 


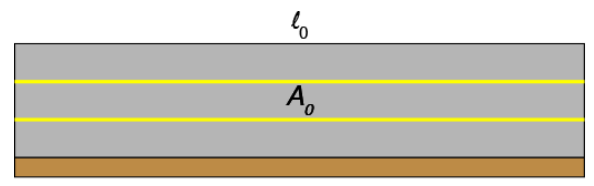

(a)

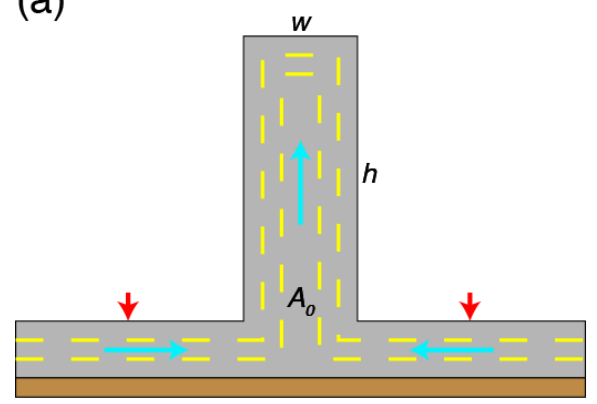

(b)

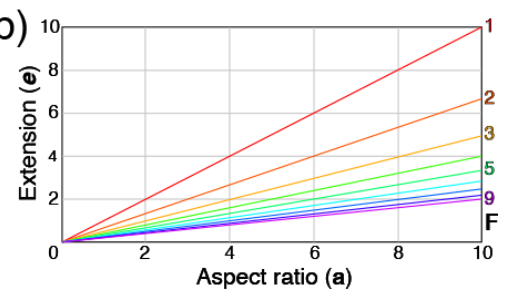

(c)
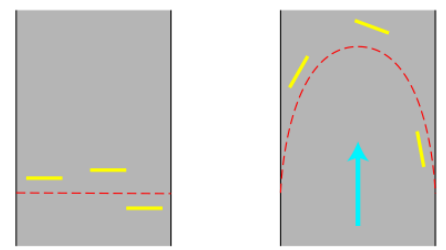

Figure 13. Conceptual diagrams of passive diapirism emphasizing the intrasalt strong layers and ignoring complex halite-dominated folding: (a) salt layer of area $A_{0}$ and with two strong layers (yellow) of length $l_{0}$ (top) is the source for salt flowing into the diapir with width $w$ and height $h$ (bottom) in a plane-strain, constant-area scenario - flow into and up the diapir (blue arrows) results in lengthening and boudinage of strong layers; (b) graph showing extension $e$ of strong layers as a function of the aspect ratio a and the fetch factor $F$ (see text); (c) Poiseuille flow up diapir, as shown by deflection of imaginary horizontal line (red, left) to its deformed equivalent (right) results in shear-induced rotation of stringers (yellow) to near-vertical orientations in most cases.
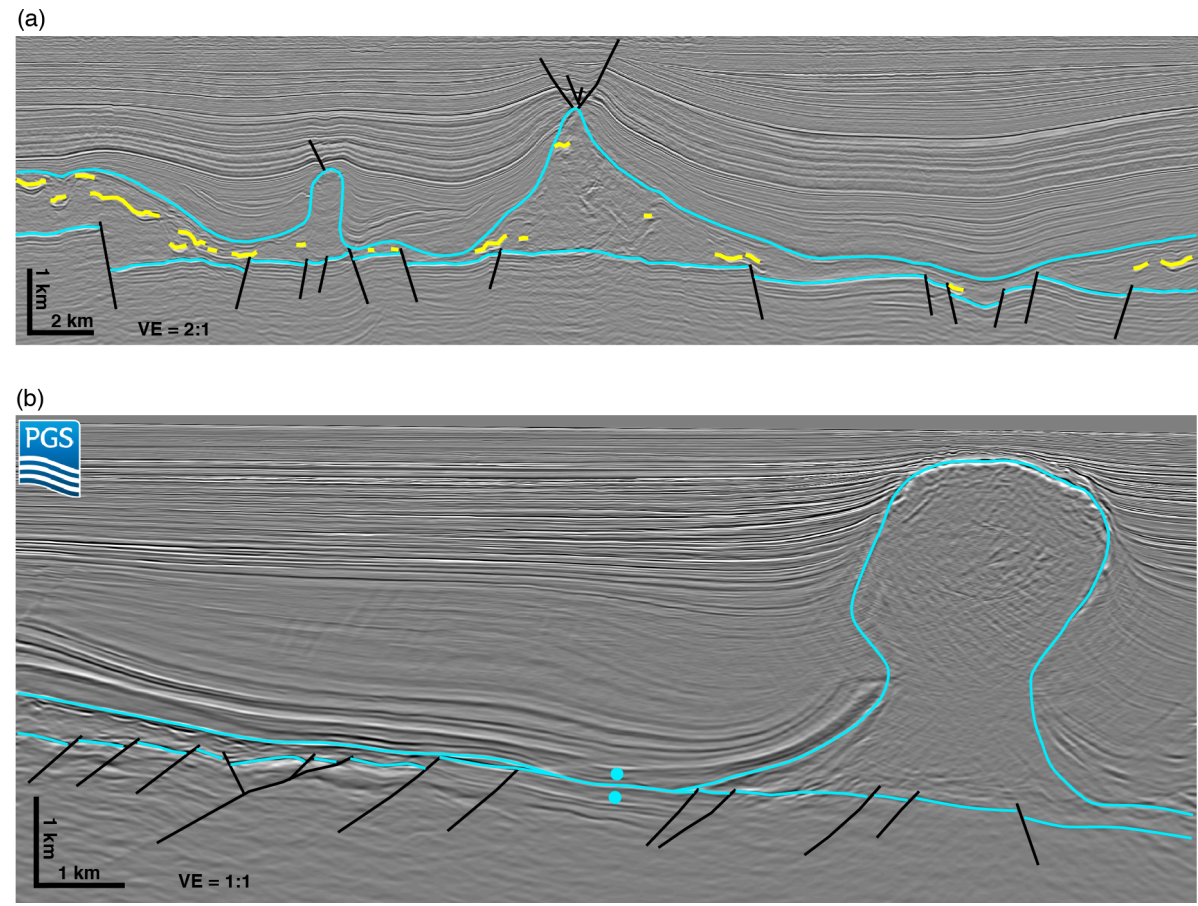

Figure 14. Examples of passive diapirs formed by LES with internal competent beds: (a) 3-D depth-migrated seismic profile (vertical exaggeration $2: 1$ ) from the Wadden Sea of the onshore Netherlands showing two diapirs formed by the Zechstein salt (between cyan horizons) - very little of the Z3 stringer (yellow) is visible within the diapirs or beneath the flanking depocenters (adapted from Strozyk et al., 2014); (b) 3-D depth-migrated seismic profile (vertical exaggeration 1:1) from the Santos Basin with expulsion-rollover structure and passive diapir (data courtesy of PGS Investigação Petrolifera Limitada). 


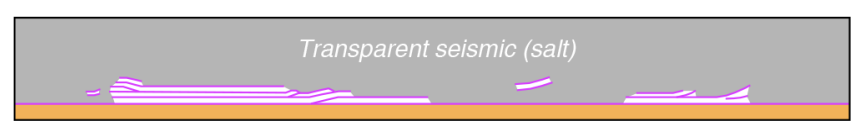

Figure 15. Simplified sketch based on observations of 3-D seismic data in the northern Red Sea. The bright package (in purple) locally at the base of the Mansiyah salt (in grey) is the Kial Formation, which includes significant proportions of anhydrite (Hughes and Johnson, 2005). The Kial has variable expression: as coherent bedding, as slightly disrupted bedding (due to thrusting), as isolated stringers near the base of salt, or absent. Thus, the base of the mobile, transparent salt (grey) cuts up and down stratigraphically.

proximal areas dominated by extension (Volozh et al., 2003, Fig. 5, panels A, D1, and D2). Recent interpretations based on 3-D seismic data interpret the top of Kungurian strata to be the top salt, with the younger successions representing minibasins that become encased in salt due to subsidence and subsequent flow of mobile salt over their tops (Fernandez et al., 2017; Duffy et al., 2017). Interestingly, the location of these possible encased minibasins is between the proximal and more distal domains of Volozh et al. (2003). We suggest that there is a complete spectrum of relationships that is dependent largely on the relative proportions of evaporites and more competent layers within the Ufimian and Kazanian sequences. Where halite is absent or rare in the younger section, these strata form brittle minibasins above the Kungurian salt, but where halite is common in the younger section, all three sequences behave as a ductile LES. In between, thicker packages of relatively halite-poor strata still form part of the LES but in a more coherent manner that appears somewhat analogous to suprasalt minibasins that become encased.

Another example is provided by the combination of the Permian and Triassic salts of the Southern Permian Basin of Europe. The Upper Permian Zechstein Group is well established as the primary mobile salt interval, but there was also halite deposition within the underlying Rotliegend Formation of northern Germany, with both the Rotliegend and Zechstein salts locally acting in concert to form diapirs (JähneKlingberg et al., 2018). Halite sequences are also common in the Buntsandstein, Muschelkalk, and Keuper sequences of the Triassic, with the main intrasalt sequences being the Buntsandstein siliciclastics and the Muschelkalk carbonates (e.g., Beutler, 1998; Geluk et al., 2000; Geluk, 2007b; McKie, 2017). The aerial and thickness distribution of Triassic halites was highly variable, which most likely influenced the local deformation. In NW Germany, for example, blocks of the Lower and Middle Buntsandstein separated by gaps have been interpreted as rafts formed during thin-skinned extension decoupled from pre-salt extension in other locales (Mohr et al., 2005). However, it is possible that some of the deformation represents intra-LES boudinage during not just extension but also salt evacuation and diapirism. If this were the case, there might be age-equivalent stringers within the larger diapirs that are unrecognized due to greater amounts of disruption and steeper attitudes.

In the Santos Basin, the onset of salt flow has been interpreted to have occurred during ongoing evaporite deposition (e.g., Davison et al., 2012; Quirk et al., 2012). However, detailed stratigraphic analyses demonstrate that the LES is mostly pre-kinematic in at least one area (Fiduk and Rowan, 2012; Jackson et al., 2014, 2015): the internal stratigraphic intervals remained parallel and undeformed, with only regional thickness changes, until near the cessation of evaporite deposition. In other basins, however, the upper portions of the LES were indeed deposited, while deeper, older portions were already moving due to extension or contraction. This is interpreted, for example, in the Zechstein salt basin (e.g., Stewart and Clark, 1999; Geluk, 2005; van Gent et al., 2011) and also in the Miocene salt of the northern Carpathians (Kolasa and Ślączka, 1985; Bukowski, 1997). Other areas where synkinematic evaporite deposition occurred include the Red Sea and Precaspian basins.

One implication of the different timing relationships concerns the interpretation of stratal thinning within the LES. Thickness variations may represent growth strata deposited during movement of underlying salt, as is typical for suprasalt minibasins. In contrast, they may be purely structural, caused by differential flow within the salt. And of course, there can be any combination of depositional and structural thinning of intrasalt strata. It is not easy to discern the difference: in the Levant Basin, apparent growth geometries are interpreted as evidence for shortening during evaporite deposition (Gvirtzman et al., 2013) but also as being due entirely to structural thinning during post-Messinian shortening (Allen et al., 2016).

\subsection{Competent-layer properties}

We have focused on the deformation of intrasalt competent beds, treating them simply as anomalous layers within the power-law-fluid halite. These strong layers are not all equal - they can differ in strength, thickness, and density. Below, we discuss the effects of varying these properties. We also address the mechanical stratigraphy of multilayers, i.e., the relative proportions and thicknesses of brittle and ductile layers within discrete stratigraphic packages.

\subsubsection{Thickness and strength}

The wavelength, or spacing, of structures is dependent on layer thickness. Boudins of thicker layers can thus be longer than those of thinner layers. In layer-parallel shortening of strong layers embedded in a weak matrix, the initial wavelength of the resultant buckle folds increases as the layer thickness increases (Ramberg, 1960; Biot, 1961).

As mentioned briefly above, the competency contrast between relatively strong layers and weak halite and bittern salts influences the style of deformation. In extension, if the 
competency contrast between the strong layer and its more ductile matrix is relatively small, pinch-and-swell structures (or drawn boudins) develop; if it is relatively large, the strong layer extends by brittle fracturing and forms torn boudins (e.g., Ramberg, 1955; Ramsay, 1967; Goscombe et al., 2004; Abe and Urai, 2012). The large contrasts within LES result in predominantly torn boudins (Figs. 2b, d and 5). Interestingly, thinner layers tend to rupture less during layer-parallel extension than thicker layers (von Hagke et al., 2018).

Differing competency contrasts also impact the mechanics of buckle folds and the consequent structural styles in shortening (e.g., Ramsay, 1982; Ramsay and Huber, 1987). When the competency contrast is low, the initial wavelength is short relative to layer thickness, the layer thickens due to layerparallel shortening (LPS), and low-amplitude cuspate-lobate folds result. When the contrast is high, the initial wavelength is long relative to layer thickness, LPS is negligible, and high-amplitude buckle folds and ultimately ptygmatic folds develop. Again, the typical large competency contrasts within LES mean that buckle and ptygmatic folds are predominant (Fig. 7a and b), but relatively weak non-evaporite layers such as overpressured mudstones are likely to provide exceptions.

\subsubsection{Mechanical stratigraphy of multilayers}

The above discussion of the role of layer thickness and strength was for single competent beds encased in a weak matrix. Typically, however, an LES can be considered as a multilayer, i.e., an interbedded sequence of rocks with different thicknesses, rheologies, and competency contrasts. Here, we focus on buckling because of the rich literature on folded multilayers (e.g., Ramberg, 1962, 1964; Ramsay and Huber, 1987; Hudleston and Treagus, 2010); presumably, there are analogous but different effects in extended multilayers.

There are numerous controls on fold geometry, the most important of which for intrasalt deformation are (1) the rheology of each layer and the contrast in rheology between layers; (2) the thickness of each layer and the grouping of layers into packages of relatively low or high competence; (3) the nature of the interfaces between layers, i.e., whether layers are effectively welded together (which is typically not the case for salt); and (4) the geometry of the bounding presalt and suprasalt strata. These combine to determine different styles of folding based largely on the relative proportions and thicknesses of strong and weak layers. If the strong layers are far enough apart that there is no interference of the ductile material adjacent to one and that adjacent to another, each folds independently and disharmonic folds result (Figs. 6b, 7b and d; Fiduk and Rowan, Fig. 9). When the weak layers are relatively thin and of similar thickness, the competent-layer thicknesses also do not vary too much, and the competence contrast is fairly consistent; the folding is largely harmonic (Fig. 7d; Fiduk and Rowan, Fig. 6; Jackson et al., 2015, Figs. 7a and 10a). However, if the ductile layers are relatively thin and the thicknesses and competency contrasts of the strong layers vary markedly, polyharmonic folds develop in which folds or thrusts of thinner competent layers are themselves folded by thicker, even stronger layers. This can also occur due to the longer-wavelength structures of the overburden deforming shorter-wavelength folds within the LES.

The mechanical stratigraphy of the LES multilayer also influences how internal strain is partitioned. There may be multiple detachment levels (Cartwright and Jackson, 2008) due to localized shear in intervals of thicker halite and/or bittern salts. The thicker weak levels also experience more Poiseuille flow than the intervening stronger packages (Cartwright et al., 2012).

\subsubsection{Density}

The effects of the strength and thickness of competent layers embedded in a ductile medium, as discussed above, are well established and accepted. However, the effects of density contrasts are less well understood and thus somewhat more controversial. Despite most intrasalt strong layers being more dense than the encasing halite (e.g., anhydrite, carbonates, most siliciclastics, volcanics), they have been carried up in diapirs and into allochthonous sheets by the mobile halite. Examples are found in salt basins throughout the world, including the Flinders Ranges of South Australia, the Oman salt basins, the Zagros Mountains of Iran, the Spanish Pyrenees, and La Popa Basin of Mexico. Analog and numerical models have suggested that once the salt movement slows or ceases, the more dense stringers sink back down through the halite (Koyi, 2001; Chemia and Koyi, 2008; Chemia et al., 2008). However, this is questioned by Van Gent et al. (2011), based on a lack of observed correlation between stringer size and depth, and numerical simulation by Li et al. (2012b) helps show why this does not occur. The explanation lies in the complex cyclic rheology of halite deformation. As mentioned above, differential stress associated with diapiric flow is approximately $2 \mathrm{MPa}$, with roughly equal contributions of pressure-solution creep and dislocation creep (Fig. 3a); that caused by density differences is about $0.1 \mathrm{MPa}$. Thus, diapiric flow can carry more dense stringers upward, and sinking is insignificant. Once flow stops, the differential stress relaxes and pressure-solution creep becomes dominant. However, the grain boundaries "freeze" and the fluid films form bubbles (Urai et al., 1986), so that pressure solution is switched off and sinking ceases. This is the case at least for the relatively small Zechstein stringers, but these stresses can rise to several MPa for large dense intrasalt packages, such as those in the Precaspian Basin.

Do density contrasts play any role in determining structural styles during ongoing deformation? Folding of strong layers driven by progradational loading is shown to be influenced by varying densities: synclines sink more in the case of more dense layers, whereas anticlines rise higher for less 
dense layers (Albertz and Ings, 2012). In contrast, other numerical models produce no such sinking of more dense anhydrite analogs (Li et al., 2012a; Raith, 2017). Dooley et al. (2015) built an analog model of a deeper pure polymer (halite) overlain by interbedded polymer and stronger and more dense granular interlayers (anhydrite). When a differential load was applied, the deep polymer level (their A1) formed internal "diapirs" and "salt sheets", while the more dense upper portion (their A2-A4) sank and formed recumbent, isoclinal folds (Fig. 16a). They ascribe this geometry to intrasalt Raleigh-Taylor overturn of two viscous materials with a density inversion combined with folding generated by allochthonous salt emplacement. This model is used to explain the observed deformation in some complex structures of the Santos Basin (Fig. 16b), interpreted to have grown by passive diapirism followed by minor late-stage shortening (Jackson et al., 2015). However, it should be kept in mind that the model material used was Newtonian viscous, in which sinking driven by density differences is much faster than in a material that deforms by power-law creep and has a much higher effective viscosity at low differential stress, i.e., one correctly scaled for salt tectonics.

In contrast, Fiduk and Rowan (2012) use a depth-migrated version of the same data from the Santos Basin to suggest that the structures are primarily contractional. Here, we suggest that the analog model of Raleigh-Taylor overturn (Fig. 16a) cannot explain the observed structures (Fig. 16b). In a simple line-length restoration of the model, all layers fit back together almost perfectly (Fig. 16c), as expected given the initial configuration and the applied boundary conditions (vertical differential loading). However, a line-length restoration of the real example shows several problems (Fig. 16d). First, the deepest layer restores to a length $3 \mathrm{~km}$ longer than the deformed-state section. One possible explanation is that the beds were lengthened during folding, but the large viscosity contrasts in the Santos Basin LES suggest that there should be little to no stretching of the strong anhydrite layers. Moreover, there is usually little observed correlative thinning in this and similar structures. Another possibility is that the approximate depth geometry is significantly off, but the generally excellent images of the pre-salt section indicate that this is unlikely. We suggest instead that there was at least $3 \mathrm{~km}$ of intrasalt shortening within this single structure. There are folds and thrusts of the overburden that extend away from the structure (see Jackson et al., 2015, Fig. 9b) but without as much shortening; as explained above, a higher level of shortening within the salt is to be expected. Second, the shallower beds all have shorter restored lengths and, moreover, the lengths are unequal. Yet, both Fiduk and Rowan (2012) and Jackson et al. (2015) agree that the initial configuration comprised parallel strata of equal lengths. The amount of missing section ranges between 1.9 and $5.7 \mathrm{~km}$, with no systematic pattern up-section. In short, the data do not match the model.
The observed geometries in the Santos Basin are also incompatible with numerical models and other real examples of inflation and passive diapirism caused by differential loading, in which internal strong layers form boudins due to the required lengthening and high-viscosity contrasts (Figs. 10 to 14). Therefore, we offer an alternative interpretation that has several key components. First, the structure of Fig. 16b was formed primarily by shortening, with only a minor component of passive diapirism due to erosional and extensional unroofing of the top of the structure. Second, the overall internal geometry is that of a breached ptygmatic fold, albeit with some disharmonic deformation. Third, the deep core of the structure is indeed made up of the deepest layer of the LES but represents the core of a contractional anticline rather than a feeder diapir to a shallow sheet. Fourth, the upper, mostly transparent part of the structure is not an allochthonous sheet made up of the A1 layer, as in the analog model; instead, it represents the upper portion of the anticline, which contains a mix of A1 and the missing portions of the shallower layers but with bedding disrupted so that there is no seismic coherency. Finally, there is no hard boundary between layered and transparent seismic facies but rather a gradual transition that we interpret as a progression from well-behaved bedding to slightly disrupted strata to a melange of strong pieces in a matrix of ductile material.

Interestingly, the synclinal portions of the structures tend to be better imaged than the anticlinal portions, implying that rupturing of the strong layers is more pronounced within the anticlines. This is incompatible with established models of folding, in which the neutral surface (boundary between local tensile and compressional stresses caused by bending of strong layers) migrates to the insides of folds, i.e., the bases of anticlines and the tops of synclines (e.g., Frehner, 2011). This puts stronger layers within both anticlines and synclines in local tension, which should lead to equal extensional breakup of bedding. We suggest that the explanation may lie in the mechanical stratigraphy of the multilayer. If the upper part of the folded stratigraphy contains more weak material (halite and especially bittern salt) and the lower part has higher-viscosity layers (as is the case for layers A2-A4 of Fig. 15b; see well logs in Jackson et al., 2014, 2015), thin strong layers within the upper portion are more likely to be stretched and broken into boudins and thus more poorly imaged. To sum up, although density contrasts may have contributed to the deformation, for example, by aiding in the breaching of the early anticline, we interpret the role as minor.

\subsection{Combined modes of salt tectonics}

We have shown that the internal deformation of salt sequences with stronger interbeds varies depending on the mode of salt tectonics. Specifically, we focused on simple extension, contraction, differential loading, and passive diapirism. However, areas that experienced exclusively one 
(a)

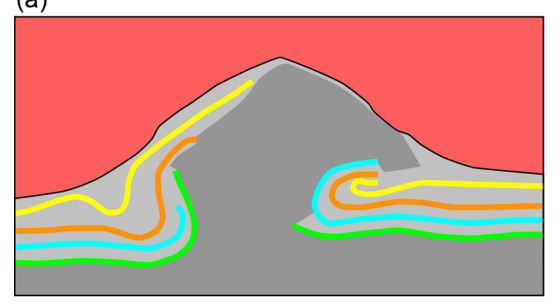

(c)

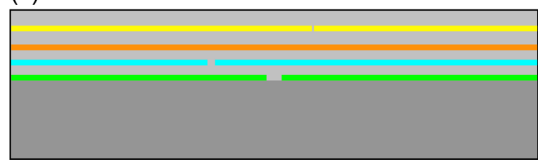

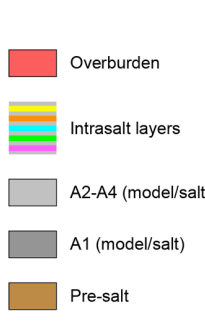

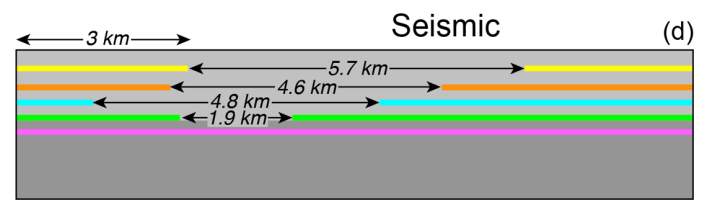

Figure 16. Analog model and seismic profile from the Santos Basin: (a) simplified results of analog model, where A1 is pure silicone polymer and A2-A4 are a mixture of polymer and stronger, more dense granular interlayers (adapted from Dooley et al., 2015); (b) time-migrated 3-D seismic profile at approximately 1: 1 scale, with the analogous A1 and A2-A4 layers (adapted from Jackson et al., 2015) - the purple line is an extra layer within the A1 unit and is part of the B3 sequence of Fiduk and Rowan, 2012); (c) line-length restoration of the analog model of panel (a) showing that layers fit back together; (d) line-length restoration of the seismic profile of panel (b), with an extra $3 \mathrm{~km}$ of the purple layer and missing lengths of the shallower layers. Restorations carried out in Move ${ }^{\mathrm{TM}}$.

mode are rare. In salt movement triggered by extension or contraction, for example, differential loading plays a contributing role because some areas of salt rise, while others sink and develop greater thicknesses of overburden. Passive diapirs usually have an early phase where salt movement was initiated by extension, contraction, or differential loading. Moreover, it is common for passive diapirs, whatever their origin, to experience late extension or contraction since they are the weakest portions of basins and thus tend to localize strain.

Nevertheless, we suggest that using the models presented here can aid in distinguishing between and understanding different styles and processes of salt-related deformation. In the following sections, we use two salt basins to illustrate and examine more complex scenarios. First, we use the Santos Basin of the Brazilian passive margin to show how the dominant style varies spatially, from proximal extension and passive diapirism to distal contraction. Second, we discuss the temporal evolution of salt tectonics in the Southern Permian Basin of Europe, from early extension to differential loading and passive diapirism and to late contractional rejuvenation.

\subsubsection{Santos Basin}

The northern half of the Santos Basin is dominated by two major salt-tectonic provinces: the mostly evacuated and welded salt of the proximal Albian Gap and the inflated and folded salt of the distal São Paulo Plateau (e.g., Modica and Brush, 2004; Quirk et al., 2012; Garcia et al., 2012; Kukla et al., 2018). We use a modern depth-migrated 3-D seismic profile to, first, describe the large-scale structural styles and domains and, second, describe the associated intrasalt deformation with reference to the models presented in this paper.
Starting at the proximal, NW end of the line and moving basinward, we identify four domains (Fig. 17). First, landward of a major step in the base salt over the Merluza fault is an expulsion-rollover structure and a vertical, symmetric passive diapir. This is an area of differential loading and diapirism, with little lateral translation because of the barrier to basinward movement provided by the $2.6 \mathrm{~km}$ offset in the base salt at the Merluza fault. Second, on the basinward side of the step is a domain dominated by extensional diapirs and faults with associated extensional rollovers (see also Fig. 5b). Faults and equivalent diapir margins dip both basinward and landward, including the large counter-regional extensional system of the Albian Gap. Third, basinward of the Albian Gap is an area of passive diapirs and synclinal minibasins but with low-angle stratal truncations and minor components of both extension and shortening. We interpret this as a transitional zone between proximal extension and distal contraction. Finally, the basinward end of the line comprises a series of anticlines and synclines over salt that is 0.4 to $1.2 \mathrm{~km}$ thick, and is the updip portion of the major São Paulo contractional domain that extends farther basinward (see also Fig. 7d).

A quick glance at the seismic profile shows that the internal character of the salt varies systematically depending on the mode of salt tectonics (Fig. 17). This is despite the fact that the entire line is in the same local part of the salt basin, where the evaporites were originally layered throughout the area. The tall passive diapir just landward of the Merluza fault is transparent, although there are several stringers visible on the lower portion of the proximal flank. Moving basinward, the salt rollers and reactive diapirs of the extensional domain are also largely transparent, although some stringers can be seen, due to disruption of the intrasalt layers by boudinage (Figs. 4 and 5). The diapirs of the transi- 

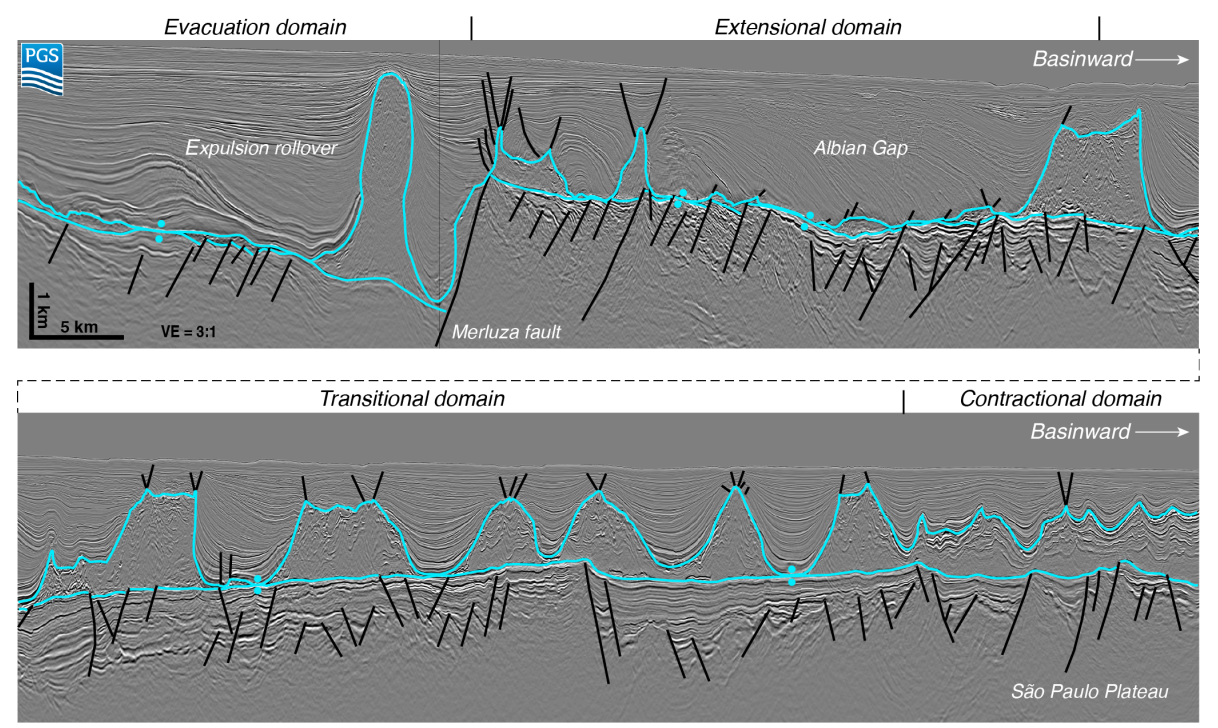

Figure 17. Regional 3-D depth-migrated seismic profile from the Santos Basin (vertical exaggeration $3: 1$ ), separated into two halves and with salt shown in cyan (data courtesy of PGS Investigação Petrolifera Limitada).

tional domain, in contrast, are characterized by more internal reflectivity, with a chaotic pattern of stringers within a background of transparent seismic facies. The relative abundance of imaged stringers is not typical of passive diapirs, but then these are not steep stocks or walls - they are generally broad salt bodies with low-angle stratal truncations on their flanks. One possibility is that the contractional component of the deformation resulted in internal folding and thus greater preservation of layer coherency, rather than the lengthening and boudinage characteristic of simple passive diapirs. Another is that these diapirs have internal deformation that is intermediate between our simple models of salt pillows and passive diapirs (Figs. 10-12 and 13-14). Finally, the distal contractional domain is marked by largely coherent and folded intrasalt layers but with thickness variations possibly due to differential flow of more ductile portions of the salt from beneath synclines into anticlinal cores. The overall pattern in this area is typical of salt sequences that have experienced minor-to-moderate amounts of shortening (Figs. 6 and 7). Note that the more complex structure of Fig. 16b is located slightly more basinward within this contractional domain. Again, salt bodies dominated by contraction tend to have more coherent intrasalt strata, whereas passive diapirs driven by differential loading have disrupted, rotated strong layers and thus more transparent seismic character.

\subsubsection{Southern Permian Basin}

Just as the same salt basin can exhibit spatial variations in the dominant mode of salt tectonics, individual salt structures commonly experience temporal variations in the dominant mode. An excellent example is the Southern Permian Basin of northern Europe, where the Permian Zechstein salt was af- fected by a complex and multiphase tectonic history. Rifting began even during evaporite deposition (e.g., Geluk, 1999; Geluk et al., 2007; Biehl et al., 2014) and continued at different stages during the Triassic (e.g., Mohr et al., 2005; Geluk, 2007a; Rowan and Krzywiec, 2014). Because extension initiated local subsidence, consequent differential loading became a contributing driver of salt movement, with a combination of extension and loading generating a series of salt pillows, passive diapirs, and minibasins. The Alpine orogeny was then responsible for contractional modification and rejuvenation of the salt structures during the Late Cretaceous and into the Cenozoic (e.g., Baldschuhn et al., 1991; de Jaeger, 2003; Krzywiec, 2006).

A 3-D depth-migrated seismic profile from the Groningen High of the Netherlands (Raith et al., 2016) illustrates some of the resulting geometries. It crosses two pillows: the Slochteren Pillow is in the common footwall to west-dipping and south-dipping pre-salt extensional faults, and the Veendam Pillow is located partly over the southern flank of an EW-trending graben and partly over the graben itself (Fig. 18). Although folding of all strata over both pillows records late contractional growth, their early histories were different. The Buntsandstein (oldest post-salt sequence) is highly asymmetric on the Slochteren Pillow, with thinner strata to the north (to some extent erosional beneath the base-Cretaceous unconformity) and thicker strata to the south suggesting early, partially decoupled extension above the footwall of the underlying south-dipping pre-salt fault. In contrast, the Buntsandstein on the Veendam Pillow is largely symmetric, with minor thinning showing that there was syndepositional inflation. This was likely due to differential loading, triggered by formation of the graben between the two pre-salt faults and consequent subsidence of the suprasalt depocenter 
between the two pillows (see modeling by Warsitzka et al., 2015).

The resulting intrasalt deformation is correspondingly broadly similar but also somewhat different within the two pillows (Fig. 18a). The Z3 intrasalt layer geometry mimics the top-salt geometry, which resulted from the combined effects of extension, subsidence and inflation driven by differential loading, and late contraction. However, it is broken into stringers, with intrasalt extension somewhat more pronounced within the extensional Slochteren Pillow and beneath the intra-pillow depocenter. The Z3 layer is more continuous within the Veendam Pillow, which formed due to early inflation and late contraction.

\subsection{Implications}

The nature of the deformation of intrasalt strong layers, and thus their distribution within the salt, has implications for several aspects of imaging and drilling through layered evaporite sequences as well as for interpreting and modeling saltrelated deformation. Below, we touch briefly on such issues as seismic and well interpretation, building velocity models, and drilling risks.

\subsubsection{Well data}

Wells drilled into and through LES can show apparently significant variations in the percentages of different lithologies encountered. For example, in a small area of the Santos Basin, Brazil, six wells show large variations in the proportions of halite, anhydrite, and bittern salts (Jackson et al., 2014, 2015). This corresponds to differences in the average densities of specific intrasalt layers, which were used to explain contrasting structural styles. A larger study of 26 wells in the same basin found similar variations in evaporite proportions (Gonzalez et al., 2016).

Local differences in original LES composition are to be expected when older parts of the salt are moving as younger portions are deposited, especially when siliciclastic rocks are interbedded with the evaporites. They are also expected on a regional scale because anhydrite is more prevalent and thicker in marginal areas of salt basins, and halite and bittern salts are more common in basin centers (Warren, 2016). Significant local variations, however, are not expected in this portion of the Santos Basin, where there is general agreement most or all of the LES is pre-kinematic (Gamboa et al., 2008; Fiduk and Rowan, 2012; Jackson et al., 2014, 2015). Moreover, evaporite deposition at any one time cannot change from one mineral to another laterally since vertical boundaries between different brine chemistries are impossible (Warren, 2016). Thus, local variations in proportion seen in wells are most likely due to deformation. Even where stronger layers within the LES largely maintain their coherency and are therefore well imaged on seismic data, preferential flow of more ductile salts will lead to structural thinning and thickening.

In short, one-dimensional samples through deformed evaporites should not be used to determine original proportions, densities, and stratigraphy. This is especially true in the case of diapirs, where, as explained above, competent beds get folded and broken into boudins and rotated to vertical. Thus, there is a sampling bias encountered in vertical wells: a stringer $100 \mathrm{~m}$ long and $10 \mathrm{~m}$ thick is more likely to be penetrated where it has low dip in the original salt layer than where it is near vertical in the diapir. Wells drilled into steep diapirs will therefore encounter higher proportions of halite than those drilled in other structures, except of course if a vertical well happens to drill along a vertical competent layer.

\subsubsection{Seismic data}

The same issues impact seismic imaging within salt structures, as discussed, for example, in the Santos Basin example (Fig. 17). Where the strong layers are disrupted, the image is degraded due to reduced seismic coherency. Again, this is especially true within steep diapirs because of more intense deformation and the near-vertical orientation of most stringers (see Jones and Davison, 2014). Thus, diapirs typically appear transparent even when other parts of the salt system display internal seismic reflectors. Seismic transparency does not imply that the diapirs are mostly or exclusively composed of halite; for example, steep diapirs in Oman have little to no internal reflectivity, yet surface exposures show that stringers are common (compare Figs. $3 \mathrm{~b}$ and 5 in Reuning et al., 2009). In any given area, diapirs, pillows, salt rollers, the cores of contractional anticlines, etc. are generally not fundamentally different in their composition, just in their seismic expression. However, this is true only for salt layers that are pre-kinematic; if LES deposition continues after the onset of salt-related deformation, there can be significant lateral variations in composition and thus seismic character.

In any case, the variability in seismic expression due to differences in the dominant mode of salt tectonics has several ramifications. First, it impacts the building of velocity models used in depth migration and imaging of sub- or presalt geometries. Two endmember options are to use a single salt velocity everywhere or to use one velocity for transparent areas, which are presumed to be halite, and another velocity for layered seismic facies. Neither of these is likely to be correct. Even approaches that combine seismic images with lithology and velocity data calibrated from wells (e.g., Barros et al., 2017) are liable to be inaccurate because the transparent areas typically include stringers of non-halite lithologies that are not imaged. In other words, the transparent and layered areas usually have less and more halite, respectively, than thought.

Second, the seismic image can be misleading to those planning and drilling wells through the salt. It is usually safer 

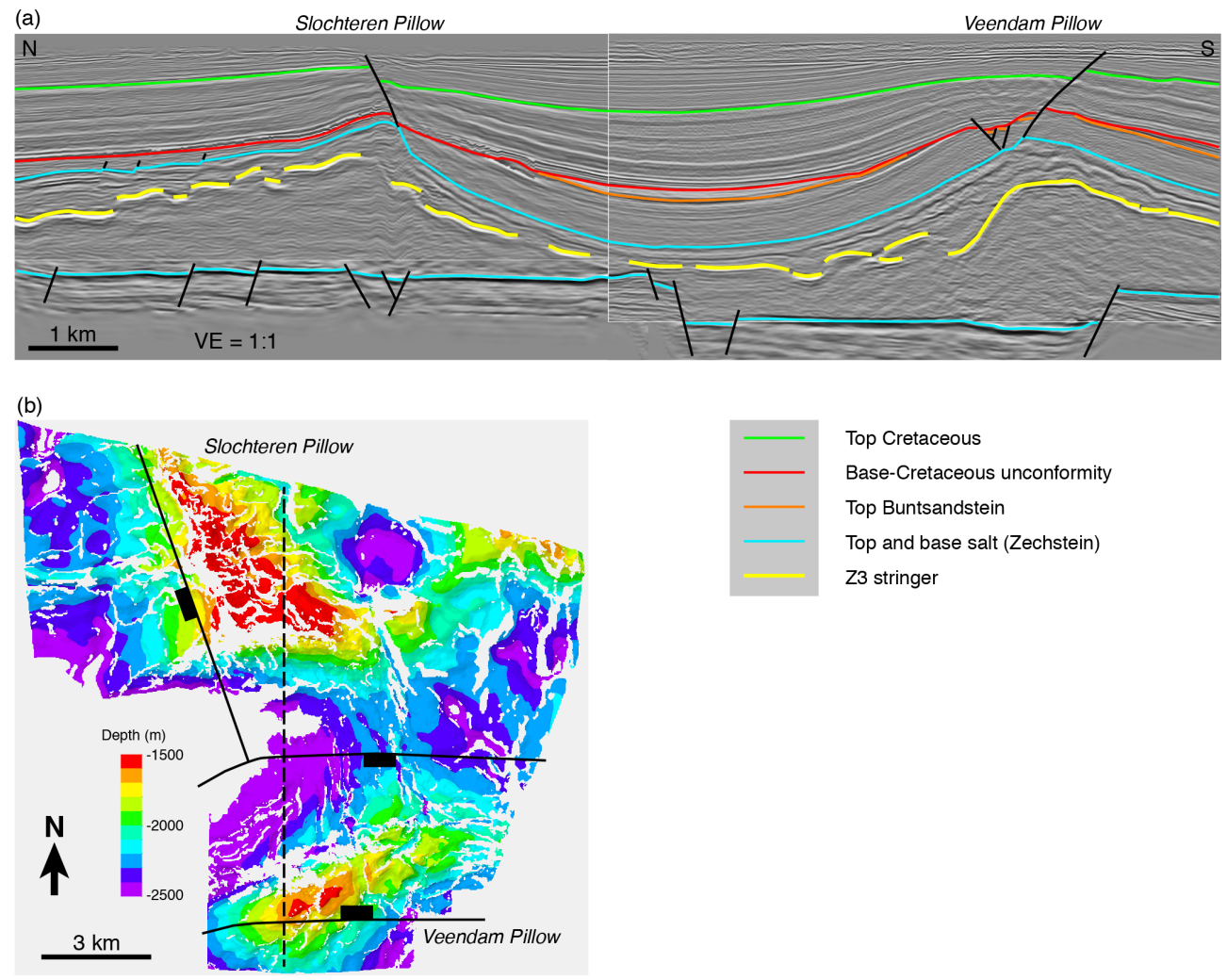

Top Cretaceous

Base-Cretaceous unconformity

Top Buntsandstein

Top and base salt (Zechstein)

Z3 stringer

Figure 18. The Slochteren and Veendam pillows on the Groningen High, the Netherlands (adapted from Raith et al., 2016): (a) 3-D depthmigrated seismic profile (vertical exaggeration $1: 1$, location shown by dashed line on map); (b) structure map of the Z3 stringer, with white representing gaps in the interpreted layer (gaps between yellow stringers on the seismic), and pre-salt extensional faults in black.

to drill through areas where there are no competent layers (see below), and wells are planned accordingly. However, the absence of an imaged stringer does not necessarily mean that the stringer is truly absent. In the Southern Permian Basin, some wells have penetrated the Z3 stringer even when it is not visible due to small size or steep dips (Van Gent et al., 2011).

Third, seismic data can be misinterpreted, with sometimes costly consequences. For example, layered evaporites may be misidentified as non-evaporite sequences and may be drilled if in a trap geometry. We know of one case in which a large turtle structure between two obvious diapirs was tested. It turned out to comprise about $70 \%-80 \%$ evaporite and $20 \%-$ $30 \%$ mudstone, with no reservoirs and no hydrocarbons. Alternatively, transparent diapirs may be misinterpreted as consisting purely of halite. In one instance, gravity models run using a standard halite density predicted that a salt diapir in the Nordkapp Basin had large overhangs and a narrow feeder, providing room for a subsalt trap. However, a well and its sidetrack both remained in salt, encountering caprock and stringers of anhydrite, carbonate, sandstone, and mudstone that were not imaged. Post-drill modeling using a higher density that reflected the contributions of anhydrite and carbon- ate supported the diapir being wider than originally thought (Stadtler et al., 2014).

\subsubsection{Drilling hazards}

Stringers can sometimes be exploration targets, such as the interbedded carbonate reservoir and source rock layers within the Ara salt of Oman (e.g., Peters et al., 2003; Reuning et al., 2009). However, the majority of wells in basins with sub- or pre-salt plays try to avoid stringers while drilling through the salt. Both fluid kicks and losses have been encountered, for example, while drilling through stringers in the Zechstein salt (Strozyk, 2017). Highly fractured carbonates can be overpressured due to the surrounding sealing salt, but normal pressures may be encountered if the fluids have had a chance to escape, for example, by contact with the suprasalt strata (e.g., Kukla et al., 2011). Additionally, there can be significant shear stresses at the boundaries between halite and strong layers (Weijermars et al., 2014), although the values calculated are unrealistically high and to our knowledge cannot occur in the subsurface. In all these potential hazards, it is important to remember that stringers are not necessarily imaged, especially in more deformed salt, presenting an unavoidable drilling risk. 


\section{Conclusions}

Layered evaporite sequences comprise different evaporites and, typically, non-evaporite layers. Most studies on intrasalt deformation have focused on halite as the dominant evaporite mineral. Here, we address instead the deformation of relatively strong layers such as interbedded anhydrites, carbonates, and siliciclastics. The effective viscosity contrasts between these strata and ductile halite and bittern salts range from 1 to over 5 orders of magnitude. As a result, the deformation of the strong layers is considerably different than the ductile flow of the more mobile evaporites. In layerparallel shortening, competent intervals tend to form concentric folds formed by bedding-parallel shear along the weak layers. In layer-parallel extension, they behave as brittle materials, breaking into stringers due to boudinage.

The layered rheological contrasts influence how salt behaves in different endmember modes of salt tectonics. In extensional settings, boudinage of strong layers dominates. Stringers are subhorizontal in weakly extended areas but become more complexly deformed as extension increases, such as in salt rollers in the footwalls of normal faults. Deeper strong layers may be more extended than shallow ones. In contrast, partly because rocks are stronger in contraction than in extension, competent layers tend to maintain coherency in low-to-moderate amounts of shortening. They form variable fold geometries (more rarely thrusts) ranging from symmetric anticline-syncline pairs to asymmetric ptygmatic folds, with disharmonic and polyharmonic styles common. Some layers within the LES may experience different amounts of shortening depending on how strain is partitioned. As salt beneath the suprasalt synclines thins and moves into the anticlines, the latter become areas of more intense folding, thrusting, and disruption.

Differential loading of salt generates areas of thinning salt and adjacent areas of salt inflation, with bulk flow from the former into the latter. As a result, boudinage is dominant beneath suprasalt depocenters and folding dominates in salt pillows. Three-dimensional convergent flow into pillows causes an additional component of tangential contraction and folding. If the salt breaks through to initiate passive diapirism, significant lengthening of intrasalt strong layers as the diapir grows in height leads to increased boudinage, with the resulting stringers rotated to near-vertical orientation and entrained in ductile salt that is strongly deformed in large-scale curtain folds and shear-related folds. The stringers rotate back to low angles if the salt subsequently advances more laterally in allochthonous sheets.

In some cases, salt may be dominated by a single style of deformation and thus fit one of the endmember models nicely. In many cases, however, more complex histories result in a progression from one mode to another, as in the case of a passive diapir that forms from an early contractional anticline, and the resultant deformation is a hybrid of the simple models. Even when one mode dominates, how- ever, greater magnitudes of deformation generally lead to increasingly complex internal geometries. Moreover, different areas of a salt basin may be characterized by different modes of salt tectonics. This is especially true of passive margins, where proximal, translational, and distal provinces are dominated, respectively, by extension, differential loading, and contraction, with resultant diapirs triggered by different mechanisms.

The variable styles and geometries of intrasalt deformation have important implications for interpreting seismic images of salt because they cause varying amounts of disruption of intrasalt strong layers and thus seismic coherency. Competent strata tend to maintain structural coherency in low-tomoderate amounts of contraction and are thus more likely to be visible, although steep fold limbs might not be imaged. The same is true, to a somewhat lesser degree, for salt pillows generated by differential loading. Extension, on the other hand, ruptures the layers into boudins: if the amount of extension is relatively minor, the stringers are typically imaged, but the salt is more transparent in salt rollers and drape folds over major pre-salt faults. The most transparent areas, however, are steep diapirs due to the large amounts of intrasalt extension, the resultant rupturing of competent beds, and the rotation of stringers to near-vertical orientation.

Similarly, the variable intrasalt deformation has implications for wells drilled through salt. Where intrasalt layers are more coherent, i.e., in contractional salt structures and salt pillows, wells are more likely to encounter the entire LES stratigraphy. However, the thicknesses encountered will rarely represent the original thicknesses due to differential flow of more ductile evaporites. Where strata are disrupted into stringers, wells drilled through apparent gaps will typically not encounter that part of the stratigraphy, although small, poorly imaged stringers might still be penetrated by accident. It is in steep diapirs where well results will be the most misrepresentative of the original stratigraphy: relatively thin stringers rotated to vertical will rarely be penetrated, so that the diapirs may be misinterpreted to comprise solely or mostly halite. In all cases, wells are one-dimensional samples through deformed salt and should not be used as indicators of the original lithology, thickness, and density distribution of the LES.

In summary, deformation of intrasalt strong layers varies considerably, just as the larger-scale salt-tectonic processes differ within and between different salt basins. We have presented an analysis of this variability based on the rheology of different layers within salt sequences, numerical and analog models, and seismic and well data. It is our hope that the ideas offered here will help both academic and industry scientists understand better the fundamental concepts as well as the practical aspects of both drilling through, and seismic imaging of, salt structures. 
Data availability. The data used in this paper include seismic images and numerical and analog models from the literature and can thus be accessed via the associated references. In addition, we use proprietary 3-D seismic data from PGS Investigação Petrolifera Limitada that can be accessed only by those whose employers license the data from PGS.

Author contributions. The concept behind this paper was originally conceived by authors MR and CF, arising out of early investigations of the Santos Basin. MR did the bulk of the writing and figure preparation, with JU primarily responsible for the section on rheology, and $\mathrm{CF}$ and PK contributing throughout the paper.

Competing interests. The authors declare that they have no conflict of interest.

Acknowledgements. First, we thank PGS, through Herman Lebit and Alastair Lewis, for permission to show some of their recent data from the Santos Basin. We are also grateful to Tim P. Dooley, Ye E. Feng, Michael R. Hudec, Christopher A.-L. Jackson, Frank J. Peel, Oriol Pla, Alexander Raith, and Frank Strozyk for original versions of their figures that were redrafted here. Michael Warsitzka provided a helpful review that improved the paper, and Midland Valley Exploration is thanked for the Move ${ }^{\mathrm{TM}}$ software. Mark G. Rowan was partially funded by the Salt-Sediment Interactive Research Consortium at The University of Texas at El Paso, run by Katherine A. Giles and sponsored by BHP-Billiton, BP, Chevron, ConocoPhillips, ExxonMobil, Hess, PGS, Repsol, and Total. Janos L. Urai and Peter A. Kukla acknowledge the German Science Foundation for funding several salt-related projects, NEDMAG for supporting the PhD work of Alexander Raith, and NAM for access to the 3-D seismic data from the Netherlands.

Review statement. This paper was edited by David Healy and reviewed by two anonymous referees.

\section{References}

Abe, S. and Urai, J. L.: Discrete element modeling of boudinage: insights on rock rheology, matrix flow, and evolution of geometry, J. Geophys. Res., 117, 12-21, https://doi.org/10.1029/2011JB008555, 2012.

Abe, S., Urai, J. L., and Kettermann, M.: Fracture patterns in non-plane strain boudinage - insights from 3-D discrete element models, J. Geophys. Res., 118, 1304-1315, https://doi.org/10.1002/jgrb.50126, 2013.

Albertz, M. and Ings, S. J.: Some consequences of mechanical stratification in basin-scale numerical models of passive-margin salt tectonics, in: Salt Tectonics, Sediments and Prospectivity, edited by: Alsop, G. I., Archer, S. G., Hartley, A. J., Grant, N. T., and Hodgkinson, R., Geol. Soc. London Spec. Publ., 363, 303-330, https://doi.org/10.1144/SP363.14, 2012.
Albrecht, H., Hunsche, U., Plischke, I., and Schulze, O.: Mapping of the mechanical properties of a salt dome, Sixth Congress of the International Association of Engineering Geology (IAEG), 6-10 August, Amsterdam, the Netherlands, 1990.

Allen, H., Jackson, C. A.-L., and Fraser, A. J.: Gravitydriven deformation of a youthful saline giant: the interplay between gliding and spreading in the Messinian basins of the Eastern Mediterranean, Petrol. Geosci., 22, 340-356, https://doi.org/10.1144/petgeo2016-034, 2016.

Alsop, G. I., Weinberger, R., Levi, T., and Marco, S.: Deformation within an exposed salt wall: recumbent folding and extrusion of evaporites in the Dead Sea Basin, J. Struct. Geol., 70, 95-118, https://doi.org/10.1016/j.jsg.2014.11.006, 2015.

Baldschuhn, R., Best, G., and Kockel, F.: Inversion tectonics in the north-west German basin, in: Generation, Accumulation, and Production of Europe's Hydrocarbons, edited by: Spencer, A. M., Spec. Publ. EAPG, 1, 149-159, 1991.

Barros, P. M., Fonseca, J. S., Silva, L. M., Maul, A., Yamamoto, T., Meneguim, T., Queiroz, L. E., Toribio, T., Martini, A. F., Gobatto, F., and González, M.: Salt heterogeneities characterization in pre-salt Santos Basin fields, Offshore Technology Conference, 24-26 October, Rio de Janeiro, Brazil, OTC-28147-MS, 2017.

Beutler, G.: Keuper, Hallesches Jahrbuch für Geowissenschaften, B6, 45-58, 1998.

Biehl, B. C., Reuning, L., Strozyk, F., and Kukla, P. A.: Origin and deformation of intra-salt sulphate layers: an example from the Dutch Zechstein (Late Permian), Int. J. Earth Sci., 103, 697-712, https://doi.org/10.1007/s00531-014-0999-4, 2014.

Biot, M. A.: Theory of folding of stratified viscoelastic media and its implications in tectonics and orogenesis, Geol. Soc. Am. Bull., 72, 1595-1620, https://doi.org/10.1130/00167606(1961)72[1595:TOFOSV]2.0.CO;2, 1961.

Bornemann, O., Behlau, J., Keller, S., Mingerzahn, G., and Schramm, M.: Standortbeschreibung Gorleben: Teil III - Ergebnisse der Erkundung des Salinars, Bundesanstalt für Geowissenschaften und Rohstoffe, Hanover, Germany, 2003.

Bosworth, W., Huchon, P., and McClay, K.: The Red Sea and Gulf of Aden Basins, J. Afr. Earth Sci., 43, 334-378, https://doi.org/10.1016/j.jafrearsci.2005.07.020, 2005.

Brun, J.-P. and Mauduit, T. P.-O.: Salt rollers: structure and kinematics from analogue modelling, Mar. Petrol. Geol., 26, 249-258, https://doi.org/10.1016/j.marpetgeo.2008.02.002, 2009.

Bukowski, K.: Sedimentation of clastic strata associated with Miocene salts in Wieliczka (Southern Poland), Slovak Geol. Mag., 3, 157-163, 1997.

Burliga, S.: Kinematics within the Kłodawa salt diapir, central Poland, in: Salt Tectonics, edited by: Alsop, G. I., Blundell, D. J., and Davison, I., Geol. Soc. London Spec. Publ., 100, 11-21, https://doi.org/10.1144/GSL.SP.1996.100.01.03, 1996.

Cailteux, J. L. H., Muchez, P., De Cuyper, J., Dewaele, S., and De Putter, T.: Origin of the megabreccias in the Katanga Copperbelt (D.R. Congo), J. Afr. Earth Sci., 140, 76-93, https://doi.org/10.1016/j.jafrearsci.2017.12.029, 2018.

Cámara, P. and Flinch, J. F.: The Southern Pyrenees: a salt-based fold-and-thrust belt, in: Permo-Triassic Salt Provinces of Europe, North Africa and the Atlantic Margins, edited by: Soto, J. I., Flinch, J. F, and Tari, G., Elsevier, Amsterdam, Netherlands, 395-415, https://doi.org/10.1016/B978-0-12-809417-4.00019-7, 2017. 
Carter, N. L. and Hansen, F. D.: Creep of rocksalt, Tectonophysics, 92, 275-333, https://doi.org/10.1016/0040-1951(83)90200-7, 1983.

Cartwright, J. and Jackson, M. P. A.: Initiation of gravitational collapse of an evaporite basin margin: the Messinian saline giant, Levant Basin, eastern Mediterranean, Geol. Soc. Am. Bull., 120, 399-413, https://doi.org/10.1130/B26081X.1, 2008.

Cartwright, J., Jackson, M., Dooley, T., and Higgins, S.: Strain partitioning in gravity-driven shortening of a thick, multilayered evaporite sequence, in: Salt Tectonics, Sediments and Prospectivity, Geol. Soc., edited by: Alsop, G. I., Archer, S. G., Hartley, A. J., Grant, N. T., and Hodgkinson, R., London, Spec. Publ., 363, 449-470, https://doi.org/10.1144/SP363.21, 2012.

Cartwright, J., Kirkham, C., Bertoni, C., Hodgson, N., and Rodriguez, K.: Direct calibration of salt sheet kinematics during gravity-driven deformation, Geology, 46, 623-626, https://doi.org/10.1130/G40219.1, 2018.

Chemia, Z. and Koyi, H.: The control of salt supply on entrainment of an anhydrite layer within a salt diapir, J. Struct. Geol., 30, 1192-1200, https://doi.org/10.1016/j.jsg.2008.06.004, 2008.

Chemia, Z., Koyi, H., and Schmeling, H.: Numerical modelling of rise and fall of a dense layer in salt diapirs, Geophys. J. Int., 172, 798-816, https://doi.org/10.1111/j.1365246X.2007.03661.x, 2008.

Chen, S., Tang, L., Jin, Z., Jia, C., and Pi, X.: Thrust and fold tectonics and the role of evaporites in deformation in the western Kuqa foreland of Tarim Basin, Northwest China, Mar. Petrol. Geol., 21, 1027-1042, https://doi.org/10.1016/j.marpetgeo.2004.01.008, 2004.

Coward, M. and Stewart, S.: Salt-influenced structures in the Mesozoic-Tertiary cover of the Southern North Sea, U.K., in: Salt Tectonics - a Global Perspective, AAPG Mem., edited by: Jackson, M. P. A., Roberts, D. G., and Snelson, S., 65, American Association of Petroleum Geologists, Tulsa, USA, 229-250, 1995.

Dahlstrom, C. D. A.: Geometric constraints derived from the law of conservation of volume and applied to evolutionary models for detachment folding, AAPG Bull., 74, 336-344, 1990.

Dalgarno, C. R. and Johnson, J. E.: Diapiric structures and Late Precambrian-Early Cambrian sedimentation in Flinders Ranges, South Australia, in: Diapirs and Diapirism, edited by: Braunstein, J., and O'Brien, G. D., AAPG Mem., 8, American Association of Petroleum Geologists, Tulsa, USA, 301-314, 1968.

Davison, I.: Geology and tectonics of the South Atlantic Brazilian salt basins, in: Deformation of the Continental Crust: The Legacy of Mike Coward, edited by: Ries, A. C., Butler, R. W. H., and Graham, R. H. Geol. Soc. London Spec. Publ., 272, 345-359, https://doi.org/10.1144/GSL.SP.2007.272.01.18, 2007.

Davison, I., Anderson, L., and Nuttall, P.: Salt deposition, loading and gravity drainage in the Campos and Santos salt basins, in: Salt Tectonics, edited by: Alsop, G. I., Archer, S. G., Hartley, A. J., Grant, N. T., and Hodgkinson, R., Sediments and Prospectivity, Geol. Soc. London Spec. Publ., 363, 159-174, https://doi.org/10.1144/SP363.8, 2012.

De Jager, J.: Inverted basins in the Netherlands, similarities and differences, Neth. J. Geosci., 82, 355-366, https://doi.org/10.1017/S0016774600020175, 2003.

Dekker, L.: Potash exploration at Malagawatch, Cape Breton, Nova Scotia, CIM Bulletin, 78, 27-32, 1985.
Dooley, T. P., Jackson, C. A.-L., Jackson, M. P. A., Hudec, M. R., and Rodriguez, C. R.: Enigmatic structures within salt walls of the Santos Basin - Part 2: Mechanical explanation from physical modelling, J. Struct. Geol., 75, 163-187, https://doi.org/10.1016/j.jsg.2015.01.009, 2015.

Duffy, O. B., Fernandez, N., Hudec, M. R., Jackson, M. P. A., Burg, G., Dooley, T. P., and Jackson, C. A.-L.: Lateral mobility of minibasins during shortening: insights from the SE Precaspian Basin, Kazakhstan, J. Struct. Geol., 97, 257-276, https://doi.org/10.1016/j.jsg.2017.02.002, 2017.

Feng, Y. E. and Reshef, M.: The Eastern Mediterranean Messinian salt - depth imaging and velocity analysis considerations, Petrol. Geosci., 22, 333-339, https://doi.org/10.1144/petgeo2015-088, 2016.

Feng, Y. E., Yankelzon, A., Steinberg, J., and Reshef, M.: Lithology and characteristics of the Messinian evaporite sequence of the deep Levant Basin, eastern Mediterranean, Mar. Geol., 376, 118 131, https://doi.org/10.1016/j.margeo.2016.04.004, 2016.

Fernandez, N., Duffy, O. B., Hudec, M. R., Jackson, M. P. A., Burg, G., Jackson, C. A.-L., and Dooley, T. P.: The origin of salt-encased sediment packages: observations from the SE Precaspian Basin (Kazakhstan), J. Struct. Geol., 97, 237-256, https://doi.org/10.1016/j.jsg.2017.01.008, 2017.

Fiduk, J. C. and Rowan, M. G.: Analysis of folding and deformation within layered evaporites in Blocks BM-S-8 \& -9, Santos Basin, Brazil, in: Salt Tectonics, edited by: Alsop, G. I., Archer, S. G., Hartley, A. J., Grant, N. T., and Hodgkinson, R., Sediments and Prospectivity, Geol. Soc. London Spec. Publ., 363, 471-487, https://doi.org/10.1144/SP363.22, 2012.

Flinch, J. F. and Soto, J. I.: Allochthonous Triassic and salt-tectonic processes in the Betic-Rif orogenic arc, in: Permo-Triassic Salt Provinces of Europe, North Africa and the Atlantic Margins, edited by: Soto, J. I., Flinch, J. F, and Tari, G., Elsevier, Amsterdam, Netherlands, 417-446, https://doi.org/10.1016/B978-012-809417-4.00020-3, 2017.

Fossen, H.: Structural Geology, Cambridge University Press, Cambridge, UK, 2010

Frehner, M.: The neutral lines in buckle folds, J. Struct. Geol., 33, 1501-1508, https://doi.org/10.1016/j.jsg.2011.07.005, 2011.

Gamboa, L. A. P., Machado, M. A. P., da Silveira, D. P., de Freitas, J. T. R., and da Silva, S. R. P.: Evaporitos estratificados no Atlântico Sul: interpretação sísmica e controle tectono-estratigráfico na Bacia de Santos, in: Sal Geologia e Tectônica, edited by: Mohriak, W., Szatmari, P., and Couto Anjos, S. M., Beca Ediçôes Ltda., São Paulo, Brazil, 340-359, 2008.

Gannaway-Dalton, C. E.: Stratigraphic and structural characterization and evolution of exposed megaflaps flanking salt diapirs, Ph.D. thesis, The Unversity of Texas at El Paso, El Paso, USA, 2019.

Garcia, S. F. de M., Letouzey, J., Rudkiewicz, J.-L., Filho, A. D., and Frizon de Lamotte, D.: Structural modeling based on sequential restoration of gravitational salt deformation in the Santos Basin (Brazil), Mar. Petrol. Geol., 35, 337-353, https://doi.org/10.1016/j.marpetgeo.2012.02.009, 2012.

Garrison, J. M. and McMillan, N. J.: Jurassic continental rift magmatism in northeast Mexico: allogenic metaigneous blocks in the El Papalote evaporite diapir, La Popa basin, Nuevo León, Mexico, in: Mesozoic Sedimentary and Tectonics History of North-Central Mexico: Geol. S. Am. Spec. Paper, edited 
by: Bartolini, C., Wilson, J. L., and Lawton, 340, 319-332, https://doi.org/10.1130/0-8137-2340-X.319, 1999.

Gaullier, V. and Vendeville, B. C.: Salt tectonics driven by sediment progradation: Part II - Radial spreading of sedimentary lobes prograding above salt, AAPG Bull., 89, 1081-1089, https://doi.org/10.1306/03310503064, 2005.

Ge, H., Jackson, M. P. A., and Vendeville, B. C.: Kinematics and dynamics of salt tectonics driven by progradation, AAPG Bull., 81, 398-423, 1997.

Geluk, M. C.: Late Permian (Zechstein) rifting in the Netherlands: models and implications for petroleum geology, Petrol. Geosci., 5, 189-199, https://doi.org/10.1144/petgeo.5.2.189, 1999.

Geluk, M. C.: Late Permian (Zechstein) carbonate facies maps, the Netherlands, Neth. J. Geosci., 79, 17-27, https://doi.org/10.17/S0016774600021545, 2000.

Geluk, M. C.: Stratigraphy and tectonics of Permo-Triassic basin in the Netherlands and surrounding area, Ph.D. thesis, Utrecht University, Utrecht, the Netherlands, 2005.

Geluk, M. C.: Permian, in: Geology of the Netherlands, edited by: Wong, T. E., Batjes, D. A. J., and de Jager, J., Royal Netherlands Academy of Arts and Sciences, Amsterdam, the Netherlands, 63-83, 2007a.

Geluk, M. C.: Triassic, in: Geology of the Netherlands, edited by: Wong, T. E., Batjes, D. A. J., and de Jager, J., Royal Netherlands Academy of Arts and Sciences, Amsterdam, the Netherlands, 85-106, 2007b.

Geluk, M. C., Brückner-Röhling, S., and Röhling, H.-G.: Salt occurrences in the Netherlands and Germany: new insights in the formation of salt basins, in: Proceedings of the 8th World Salt Symposium, edited by: Geertman, R. M., Elsevier, Amsterdam, the Netherlands, 126-131, 2000.

Geluk, M. C., Paar, W. A., and Fokker, P. A.: Salt, in: Geology of the Netherlands, edited by: Wong, T. E., Batjes, D. A. J., and de Jager, J., Royal Netherlands Academy of Arts and Sciences, Amsterdam, the Netherlands, 283-294, 2007.

González, M., Gobatto, F., Maul, A., Falcão, L., González, G., Oliveira, L. C., Meneguim, T., and Amaral, P. J.: Proposed workflow to incorporate stratification within salt section using velocity and seismic attributes, Third EAGE/SBFG Workshop, 67 April, Rio de Janeiro, Brazil, https://doi.org/10.3997/22144609.201600050, 2016.

Goscombe, B. D., Passchier, C. W., and Hand, M.: Boudinage classification: end-member boudin types and modified boudin structures, J. Struct. Geol., 26, 739-763, https://doi.org/10.1016/j.jsg.2003.08.015, 2004.

Gralla, P. and Marsky, J.: Seismic reveals new eastern Pre-caspian target, Oil Gas J., 98, 86-89, 2000.

Gvirtzman, Z., Reshef, M., Buch-Leviatan, O., and Ben-Avraham, Z.: Intense salt deformation in the Levant Basin in the middle of the Messinian Salinity Crisis, Earth Planet. Sc. Lett., 379, 108119, https://doi.org/10.1016/j.epsl.2013.07.018, 2013.

Hearon IV, T. E., Rowan, M. G., Lawton, T. G., Hannah, P. T., and Giles, K. A.: Geology and tectonics of Neoproterozoic salt diapirs and salt sheets in the eastern Willouran Ranges, South Australia, Bas. Res., 27, 183-207, https://doi.org/10.1111/bre.12067, 2015.

Hill, R.: The elastic behaviour of a crystalline aggregate, Proc. Phys. Soc. A, 65, 349-354, https://doi.org/10.1088/03701298/65/5/307, 1952.
Hite, R. J. and Buckner, D. H.: Stratigraphic correlations, facies concepts, and cyclicity in Pennsylvanian rocks of the Paradox Basin, in: Geology of the Paradox Basin, edited by: Wiegand, D. L., Rocky Mountain Association of Geologists, Denver, USA, 147-159, 1981.

Hofrichter, E.: Probleme der Endlagerung radioaktiver Abfälle in Salzformazionen, Z. Dtsch. Ges. Geowiss., 131, 409-430, 1980.

Hudec, M. R. and Jackson, M. P. A.: Advance of allochthonous salt sheets in passive margins and orogens, AAPG Bull., 90, 15351564, https://doi.org/10.1306/05080605143, 2006.

Hudleston, P. J. and Treagus, S. H.: Information from folds: a review, J. Struct. Geol., 32, 2042-2071, https://doi.org/10.1016/j.jsg.2010.08.011, 2010.

Hudson, S. M., Tuttle, T., and Wood, M.: Source within the seal - distribution and implications of organic-rich shale-bearing stringers within the Onion Creek diapir, northern Paradox Basin, Utah, Geology of the Intermountain West, 4, 215-229, 2017.

Hughes, G. W. ap G., and Johnson, R. S.: Lithostratigraphy of the Red Sea region, GeoArabia, 10, 49-126, 2005.

Jackson, C. A.-L., Jackson, M. P. A., Hudec, M. R., and Rodriguez, C. R.: Internal structure, kinematics, and growth of a salt wall: insights from 3D seismic reflection data, Geology, 42, 307-310, https://doi.org/10.1130/G34865.1, 2014.

Jackson, C. A.-L., Jackson, M. P. A., Hudec, M. R., and Rodriguez, C. R.: Enigmatic structures within salt walls of the Santos Basin - Part 1: Geometry and kinematics from 3D seismic reflection and well data: J. Struct. Geol., 75, 135-162, https://doi.org/10.1016/j.jsg.2015.01.010, 2015.

Jackson, M. P. A. and Hudec, M. R.: Salt Tectonics - Principles and Practice, Cambridge University Press, Cambridge, UK, 2017.

Jackson, M. P. A., Cornelius, R. R., Craig, C. H., Gansser, A., Stöcklin, J., and Talbot, C. J.: Salt Diapirs of the Great Kavir, Central Iran, Geol. Soc. Am. Mem., 177, Geological Society of America, Boulder, USA, 1990.

Jähne-Klingberg, F., Warsitzka, M., and Lutz, R.: Distribution, tectonic structures and deformation processes of salt-bearing Rotliegend formations in the German North Sea and surrounding areas, 17th Symposium of Tectonics, 19-25 March, Jena, Germany, Structural Geology and Crystalline Geology, 2018.

Jones, I. F. and Davison, I.: Seismic imaging in and around salt bodies, Interpretation, 2, SL1-SL20, https://doi.org/10.1190/INT2014-0033.1, 2014.

Karlo, J. F., van Buchem, F. S. P., Moen, J., and Milroy, K.: Triassicage salt tectonics of the Central North Sea, Interpretation, 2, SM19-SM28, https://doi.org/10.1190/INT-2014-0032.1, 2014.

Kolasa, K. and Ślączka, A.: Sedimentary salt megabreccias exposed in the Wieliczka mine, Fore-Carpathian Depression, Acta Geol. Pol., 35, 221-230, 1985.

Koyi, H. A.: Modeling the influence of sinking anhydrite blocks on salt diapirs targeted for hazardous waste disposal, Geology, 29, 387-390, https://doi.org/10.1130/00917613(2001)029<0387:MTIOSA>2.0.CO;2, 2001.

Krzywiec, P.: Structural inversion of the Pomeranian and Kuiavian segments of the Mid-Polish Trough - lateral variations in timing and structural style, Geol. Q., 50, 151-168, 2006.

Krzywiec, P., Rowan, M. G., and Bukowski, K.: Miocene evaporites of the Carpathian foredeep basin and their role in contractional salt tectonics - 250 years of perspective, EGU Geophys. Res. Abstr., 20, EGU2018-4972, 2018. 
Kukla, P. A., Reuning, L., Becker, S., Urai, J. L., and Schoenherr, J.: Distribution and mechanisms of overpressure generation and deflation in the late Neoproterozoic to early Cambrian South Oman Salt Basin, Geofluids, 11, 349-361, https://doi.org/10.1111/j.1468-8123.2011.00340.x, 2011.

Kukla, P. A., Strozyk, F., and Mohriak, W. U.: South Atlantic salt basins - witnesses of complex passive margin evolution, Gondwana Res., 53, 41-57, https://doi.org/10.1016/j.gr.2017.03.012, 2018.

Lawton, T. F., Vega, F. J., Giles, K. A., and Rosales-Dominguez, C.: Stratigraphy and origin of the La Popa Basin, Nuevo León and Coahuila, Mexico, in: The Western Gulf of Mexico Basin: Tectonics, Sedimentary Basins, and Petroleum Systems, edited by: Bartolini, C., Buffler, R. T., and Cantú-Chapa, A., AAPG Mem., 75, 219-240, 2001.

Li, J., Webb, A. A. G., Mao, X., Eckhoff, I., Colón, C., Zhang, K., and He, D.: Active surface salt structures of the western Kuqa fold-thrust belt, northwestern China, Geosphere, 10, 1219-1234, https://doi.org/10.1130/GES01021.1, 2014.

Li, S., Abe, S., Reuning, L., Becker, S., Urai, J. L., and Kukla, P. A.: Numerical modelling of the displacement and deformation of embedded rock bodies during salt tectonics: a case study from the South Oman Salt Basin, in: Salt Tectonics, Sediments and Prospectivity, edited by: Alsop, G. I., Archer, S. G., Hartley, A. J., Grant, N. T., and Hodgkinson, R., Geol. Soc. London Spec. Publ., 363, 503-520, https://doi.org/10.1144/SP363.24, 2012a.

Li, S.-Y., Abe, S., Urai, J. L., Strozyk, F., Kukla, P. A., and van Gent, H.: A method to evaluate long-term rheology of Zechstein salt in the Tertiary, in: Mechanical Behavior of Salt VII, edited by: Bérest, P., Ghoreychi, M., Hadj-Hassen, F., and Tijani, M., CRC Press, London, UK, 215-220, https://doi.org/10.1201/b1204133, 2012b.

Mattes, B. W. and Conway Morris, S.: Carbonate/evaporite deposition in the Late Precambrian-Early Cambrian Ara formation of Southern Oman, in: The Geology and Tectonics of the Oman Region, edited by: Robertson, A. H. F., Searle, M. P., and Ries, A. C., Geol. Soc. London, Spec. Publ., 49, 617-636, https://doi.org/10.1144/GSL.SP.1992.049.01.37, 1990.

McKie, T.: Paleogeographic evolution of latest Permian and Triassic salt basins in northwest Europe, in: Permo-Triassic Salt Provinces of Europe, North Africa and the Atlantic Margins, edited by: Soto, J. I., Flinch, J. F, and Tari, G., Elsevier, Amsterdam, the Netherlands, 159-173, https://doi.org/10.1016/B978-012-809417-4.00008-2, 2017.

Modica, C. J. and Brush, E. R.: Postrift sequence stratigraphy, paleogeography, and fill history of the deep-water Santos Basin, offshore southeast Brazil, AAPG Bull., 88, 923-945, https://doi.org/10.1306/01220403043, 2004.

Mohr, M., Kukla, P. A., Urai, J. L., and Bresser, G.: Multiphase salt tectonic evolution in NW Germany: seismic interpretation and retro-deformation, Int. J. Earth Sci., 94, 917-940, https://doi.org/10.1007/s00531-005-0039-5, 2005.

Peters, J. M., Filbrandt, J. B., Grotzinger, J. P., Newall, M. J., Shuster, M. W., and Al-Siyabi, H. A.: Surface-piercing salt domes of interior North Oman, and their significance for the Ara carbonate 'stringer' hydrocarbon play, GeoArabia, 8, 231-270, 2003.

Pla, O., Roca, E., Xie, H., Izquierdo-Llavall, E., Muñoz, J. A., Rowan, M. G., Ferrer, O., Gratacós, O., Yuan, N., and Huang, S.: Influence of syntectonic sedimentation and décollement rhe- ology on the geometry and evolution of orogenic wedges: analogue modeling of the Kuqa fold-and-thrust belt (NW China), Tectonics, in review, 2019.

Quirk, D. G., Schødt, N., Lassen, B., Ings, S. J., Hsu, D., Hirsch, K. K., and Von Nicolai, C.: Salt tectonics on passive margins: examples from Santos, Campos and Kwanza basins, in: Salt Tectonics, Sediments and Prospectivity, edited by: Alsop, G. I., Archer, S. G., Hartley, A. J., Grant, N. T., and Hodgkinson, R., Geol. Soc. London Spec. Publ., 363, 207-244, https://doi.org/10.1144/SP363.10, 2012.

Raith, A. S. F.: Internal deformation of salt bodies with large mechanical contrast: a case study of the Veendam salt pillow, the Netherlands, Ph.D. thesis, RWTH Aachen University, Aachen, Germany, 2017.

Raith, A. F., Strozyk, F., Visser, J., and Urai, J. L.: Evolution of rheologically heterogeneous salt structures: a case study from the NE Netherlands, Solid Earth, 7, 67-82, https://doi.org/10.5194/se-7-67-2016, 2016.

Ramberg, H.: Natural and experimental boudinage and pinch-andswell structures, J. Geol., 63, 512-526, 1955.

Ramberg, H.: Relationship between length of arc and thickness of ptygmatically folded veins, Am. J. Sci., 258, 36-46, https://doi.org/10.2475/ajs.258.1.36, 1960.

Ramberg, H.: Contact strain and folding instability of a multilayered body under compression, Geol. Rundsch., 51, 405-439, https://doi.org/10.1007/BF01820010, 1962.

Ramberg, H.: Selective buckling of composite layers with contrasted rheological properties, a theory for simultaneous development of several orders of folds, Tectonophysics, 1, 307-341, https://doi.org/10.1016/0040-1951(64)90020-4, 1964.

Ramsay, J. G.: Folding and fracturing of rocks, McGraw-Hill, New York, USA, 1967

Ramsay, J. G.: Rock ductility and its influence on the development of tectonic structures in mountain belts, in: Mountain Building Processes, edited by: Hsü, K., Academic Press, London, UK, 111-127, 1982.

Ramsay, J. G. and Huber, M. I.: The Techniques of Modern Structural Geology, Volume 2: Folds and Fractures, Academic Press, London, UK, 1987.

Rasmussen, D. L.: Namakiers in Triassic and Permian formations in the Paradox Basin (USA) with comparisons to modern examples in the Zagros fold belt, Iran, in: Geology of Utah's Far South, edited by: MacLean, J. S., Biek, R. F., and Huntoon, J. E., Utah Geological Association Publication 43, 689-756, 2014.

Reuning, L., Schoenherr, J., Heimann, A., Urai. J. L., Littke, R., Kukla, P. A., and Rawahi, Z.: Constraints on the diagenesis, stratigraphy and internal dynamics of the surface-piercing salt domes in the Ghaba Salt Basin (Oman): a comparison to the Ara Group in the South Oman Salt Basin, GeoArabia, 14, 83-120, 2009.

Richter-Bernburg, G.: Salt tectonics, interior structures of salt bodies, B. Cent. Rech. Expl., 4, 373-393, 1980.

Rowan, M. G.: Passive-margin salt basins: hyperextension, evaporite deposition, and salt tectonics, Basin Res., 26, 154-182, https://doi.org/10.1111/bre.12043, 2014.

Rowan, M. G. and Krzywiec, P.: The Szamotuły salt diapir and Mid-Polish Trough: decoupling during both Triassic-Jurassic rifting and Alpine inversion, Interpretation, 2, SM1-SM18, https://doi.org/10.1190/INT-2014-0028.1, 2014. 
Rowan, M. G. and Linds $\varnothing$, S.: Salt tectonics of the Norwegian Barents Sea and northeast Greenland shelf, in: Permo-Triassic Salt Provinces of Europe, North Africa and the Atlantic Margins, edited by: Soto, J. I., Flinch, J. F, and Tari, G., Elsevier, Amsterdam, the Netherlands, 265-286, https://doi.org/10.1016/B978-012-809417-4.00013-6, 2017.

Rowan, M. G., Jackson, M. P. A., and Trudgill, B. D.: Salt-related fault families and fault welds in the northern Gulf of Mexico, AAPG Bull., 83, 1454-1484, 1999.

Rowan, M. G., Hearon IV, T. E., Kernen, R. A., Giles, K. A., Gannaway-Dalton, C. E., Williams, N. J., Fiduk, J. C., Lawton, T. F., Hannah, P. T., and Fischer, M. P.: A review of allochthonous salt tectonics in the Flinders and Willouran ranges, South Australia, Austral. J. Earth Sci., https://doi.org/10.1080/08120099.2018.1553063, 2019.

Salvador, A.: Triassic-Jurassic, in: The Gulf of Mexico Basin, The Geology of North America, edited by: Salvador, A., Geological Society of America, Boulder, USA, 131-180, 1991.

Schachl, E.: Exkursion G - Kali- und Steinsalzbergwerk Niedersachsen-Riedel der Kali und Salz AG, Schachtanlage Riedel: Zechsteinstratigraphie und Innenbau des Salzstocks von Wathlingen-Hänigsen, in: Exkursionsführer I - Zechsteinsalinare und Bohrkernausstellungen, edited by: Kulick, J. and Paul, J., International Symposium Zechstein, Wiesbaden, Germany, 69100, 1987.

Schléder, Z. and Urai, J. L.: Microstructural evolution of deformation-modified primary halite from the Middle Triassic Röt Formation at Hengelo, the Netherlands, Int. J. Earth Sci., 94, 941-956, https://doi.org/10.1007/s00531-005-0503-2, 2005.

Schléder, Z. and Urai, J. L.: Deformation and recrystallization mechanisms in mylonitic shear zones in naturally deformed extrusive Eocene-Oligocene rocksalt from Eyvanekey plateau and Garmsar hills (central Iran), J. Struct. Geol., 29, 241-255, https://doi.org/10.1016/j.jsg.2006.08.014, 2007.

Schmalholz, S. M. and Urai, J.: Rheology of anhydrite during deformation in nature: a first look, EGU General Assembly, Vienna, Austria, 27 April-2 May, EGU2014-14871, 2014.

Spiers, C. J. and Carter, N. L.: Microphysics of rocksalt flow in nature, in: The Mechanical Behavior of Salt: Proceedings of the 4th Conference, edited by: Aubertin, M. and Hardy, H. R., Series on Rock and Soil Mechanics, Trans Tech Publications, ClausthalZellerfeld, 22, 115-128, 1998.

Stadtler, C., Fichler, C., Hokstad, K., Myrlund, E. A., Wienecke, S., and Fotland, B.: Improved salt imaging in a basin context by high resolution potential field data: Nordkapp Basin, Barents Sea, Geophys. Prospect., 62, 615-630, https://doi.org/10.1111/13652478.12101, 2014.

Stewart, S. A.: Geometry of thin-skinned tectonic systems in relation to detachment layer thickness in sedimentary basins, Tectonics, 18, 719-732, https://doi.org/10.1029/1999TC900018, 1999.

Strozyk, F.: The internal structure of the Zechstein salt and related drilling risks in the northern Netherlands, in: Permo-Triassic Salt Provinces of Europe, North Africa and the Atlantic Margins, edited by: Soto, J. I., Flinch, J. F, and Tari, G., Elsevier, Amsterdam, the Netherlands, 115-128, https://doi.org/10.1016/B978-012-809417-4.00006-9, 2017.

Strozyk, F., Van Gent, H., Urai, J. L., and Kukla, P. A.: 3D seismic study of complex intra-salt deformation: an example from the Upper Permian Zechstein 3 stringer, western Dutch off- shore, in: Salt Tectonics, Sediments and Prospectivity, edited by: Alsop, G. I., Archer, S. G., Hartley, A. J., Grant, N. T., and Hodgkinson, R., Geol. Soc. London Spec. Publ., 363, 489-501, https://doi.org/10.1144/SP363.23, 2012.

Strozyk, F., Urai, J. L., van Gent, H., de Keijzer, M., and Kukla, P. A.: Regional variations in the structure of the Permian Zechstein 3 intrasalt stringer in the northern Netherlands: 3D seismic interpretation and implications for salt tectonic evolution, Interpretation, 2, SM101-SM117, https://doi.org/10.1190/INT-20140037.1, 2014.

Talbot, C. J.: Extrusions of Hormuz salt in Iran, in: Lyell: the Past is the Key to the Present, edited by: Blundell, D. J. and Scott, A. C., Geol. Soc. London Spec. Publ., 143, 315-334, https://doi.org/10.1144/GSL.SP1998.143.01.21, 1998.

Talbot, C. J. and Jackson, M. P. A.: Internal kinematics of salt diapirs, AAPG Bull., 71, 1068-1093, 1987.

Tubbs Jr, R. E., Aly Fouda, H. G., Afifi, A. M., Raterman, N. S., Hughes, G. W., and Fadolalkarem, Y. K.: Midyan Peninsula, northern Red Sea, Saudi Arabia: seismic imaging and regional interpretation, GeoArabia, 19, 165-184, 2014.

Urai, J. L.: Water-assisted dynamic recrystallization and weakening in polycrystalline bischofite, Tectonophysics, 96, 125-157, https://doi.org/10.1016/0040-1951(83)90247-0, 1983.

Urai, J. L.: Water-enhanced dynamic recrystallization and solution transfer in experimentally deformed carnallite, Tectonophysics, 120, 285-317, https://doi.org/10.1016/0040-1951(85)90055-1, 1985.

Urai, J. L., Spiers, C. J., Zwart, H. J., and Lister, G. S.: Weakening of rock salt by water during long-term creep, Nature, 324, 554557, https://doi.org/10.1038/32455, 1986.

Urai, J. L., Schléder, Z., Spiers, C. J., and Kukla, P. A.: Flow and transport properties of salt rocks, in: Dynamics of Complex Intracontinental Basins: The Central European Basin System, edited by: Littke, R., Bayer, U., Gajewski, D., and Nelskamp, S., Springer-Verlag, Berlin Heidelberg, 277-290, 2008.

Van Adrichem-Boogaert, H. A. and Kouwe, W. F. P.: Stratigraphic nomenclature of the Netherlands; revision and update by RGD and NOGEPA, TNO-NITG, Mededelingen Rijks Geologische Dienst, Haarlem, 50, 50, 1994.

Van Gent, H., Urai, J. L., and de Keijzer, M.: The internal geometry of salt structures - a first look using 3D seismic data from the Zechstein of the Netherlands, J. Struct. Geol., 33, 292-311, https://doi.org/10.1016/j.jsg.2010.07.005, 2011.

Vendeville, B. C. and Jackson, M. P. A.: The rise of diapirs during thin-skinned extension, Mar. Petrol. Geol., 9, 331-353, https://doi.org/10.1016/0264-8172(92)90047-I, 1992.

Volozh, Y., Talbot, C., and Ismail-Zadeh, A.: Salt structures and hydrocarbons in the Pricaspian basin, AAPG Bull., 87, 313-334, https://doi.org/10.1306/09060200896, 2003.

von Hagke, C., Bamberg, B., Virgo, S., and Urai, J. L.: Outcrop-scale tomography: insights into the 3D structure of multiphase boudins, J. Struct. Geol., 115, 311-317, https://doi.org/10.1016/j.jsg.2018.02.014, 2018.

Wade, J. A. and MacLean, B. C.: The geology of the southeastern margin of Canada, in: Geology of the Continental Margin of Eastern Canada, Geology of Canada no. 2, edited by: Keen, M. J. and Williams, G. L., Geological Survey of Canada, Ottawa, Canada, 167-238, 1990. 
Wagner III, B. H. and Jackson, M. P. A.: Viscous flow during salt welding, Tectonophysics, 210, 309-326, https://doi.org/10.1016/j.tecto.2011.07.012, 2011.

Warren, J. K.: Evaporites: A Geological Compendium, 2nd edn., Springer, Berlin, Germany, 2016.

Warsitzka, M., Kley, J., and Kukowski, N.: Analogue experiments of salt flow and pillow growth due to basement faulting and differential loading, Solid Earth, 6, 9-31, https://doi.org/10.5194/se-6-9-2015, 2015.

Wegmann, C. E.: Note sur le boudinage, B. Soc. Geol. Fr., 2, 477$491,1932$.
Weijermars, R., Jackson, M. P. A., and Vendeville, B. C.: Rheological and tectonic modeling of salt tectonic provinces, Tectonophysics, 217, 143-174, https://doi.org/10.1016/0040 1951(93)90208-2, 1993.

Weijermars, R., Jackson, M. P. A., and Dooley, T. P.: Quantifying drag on wellbore casings in moving salt sheets, Geophys. J. Int., 198, 965-977, https://doi.org/10.1093/gji/ggu174, 2014.

Zulauf, J., Zulauf, G., Kraus, R., Gutiérrez-Alonso, G., and Zanella, F.: The origin of tablet boudinage: results from experiments using power-law rock analogs, Tectonophysics, 510, 327-336, https://doi.org/10.1016/j.tecto.2011.07.013, 2011. 